\title{
An Overview of the Management of the Most Important Invasive Fungal Infections in Patients with Blood Malignancies
}

This article was published in the following Dove Press journal:

Infection and Drug Resistance

\author{
Aref Shariati (D) \\ Alireza Moradabadi ${ }^{2}$ \\ Zahra Chegini ${ }^{3}$ \\ Amin Khoshbayan (1D ${ }^{4}$ \\ Mojtaba Didehdar ${ }^{2}$ \\ 'Department of Microbiology, School of \\ Medicine, Shahid Beheshti University of \\ Medical Sciences, Tehran, Iran; \\ ${ }^{2}$ Department of Medical Parasitology and \\ Mycology, Arak University of Medical \\ Sciences, Arak, Iran; ${ }^{3}$ Department of \\ Microbiology, School of Medicine, Iran \\ University of Medical Sciences, Tehran, \\ Iran; ${ }^{4}$ Student Research Committee, Iran \\ University of Medical Sciences, Tehran, \\ Iran
}

\begin{abstract}
In patients with hematologic malignancies due to immune system disorders, especially persistent febrile neutropenia, invasive fungal infections (IFI) occur with high mortality. Aspergillosis, candidiasis, fusariosis, mucormycosis, cryptococcosis and trichosporonosis are the most important infections reported in patients with hematologic malignancies that undergo hematopoietic stem cell transplantation. These infections are caused by opportunistic fungal pathogens that do not cause severe issues in healthy individuals, but in patients with hematologic malignancies lead to disseminated infection with different clinical manifestations. Prophylaxis and creating a safe environment with proper filters and air pressure for patients to avoid contact with the pathogens in the surrounding environment can prevent IFI. Furthermore, due to the absence of specific symptoms in IFI, rapid and accurate diagnosis reduces the mortality rate of these infections and using molecular techniques along with standard mycological methods will improve the diagnosis of disseminated fungal infection in patients with hematologic disorders. Amphotericin B products, extended-spectrum azoles, and echinocandins are the essential drugs to control invasive fungal infections in patients with hematologic malignancies, and according to various conditions of patients, different results of treatment with these drugs have been reported in different studies. On the other hand, drug resistance in recent years has led to therapeutic failures and deaths in patients with blood malignancies, which indicates the need for antifungal susceptibility tests to use appropriate therapies. Life-threatening fungal infections have become more prevalent in patients with hematologic malignancies in recent years due to the emergence of new risk factors, new species, and increased drug resistance. Therefore, in this review, we discuss the different dimensions of the most critical invasive fungal infections in patients with hematologic malignancies and present a list of these infections with different clinical manifestations, treatment, and outcomes.
\end{abstract}

Keywords: invasive fungal infection, blood malignancies, aspergillosis, candidiasis, fusariosis, mucormycosis, cryptococcosis, trichosporonosis

\section{Introduction}

Blood malignancies involve myeloid and lymphoid linages in the chronic or acute phase. In the acute form, the maturation arrest at the early stage of myeloid linage occurs, and mature cells fail to be produced. Nevertheless, the chronic form is characterized by the relentless accumulation of mature cells without apoptosis. ${ }^{1}$ Acute myeloid leukemia (AML) and myeloproliferative disorders (MPDs) are related to the acute and chronic form of myeloid linage disorder, respectively. ${ }^{2}$ Furthermore, acute lymphoblastic leukemia (ALL) and lymphoproliferative disorders (LPD) are
Correspondence: Mojtaba Didehdar Department of Medical Parasitology and Mycology, Arak University of Medical Sciences, Arak, Iran

Email didehdar_m@Arakmu.ac.ir 
classified as acute and chronic lymphoid linage disorder, respectively. Another form of blood malignancy is dysplastic syndromes (MDs), mostly occur in myeloid linage, characterized by dysplasia in this linage. ${ }^{1,2}$ All of the blood malignancies involve the immune system. In patients with blood malignancies, it is more common to encounter opportunistic infections mainly invasive fungal infections (IFIs). ${ }^{3}$ Other conditions in these malignancies are bone marrow transplantations (BMT), which have the highest rate of IFIs, with the incidence range of 5 to $20 \%$ in different studies. ${ }^{4}$ LPDs are malignancy of elderlies, $70 \%$ of the patients are older than 65 years, characterized by a different grade of immunodeficiency with enhanced susceptibility to opportunistic diseases. $^{5}$

In recent years, new drugs used in the treatment of blood malignancy are the main causes of susceptibility to IFIs. The B-cell receptor signaling pathway inhibitors (BCRi) are targeting therapies in LPD, and these drugs have high efficacy in treatment, relapse prevention, and refractory resistance. Among these drugs, the most important one is ibrutinib, a Bruton tyrosine kinase (BTK) inhibitor that blocks the $\mathrm{B}$ cell receptor signaling and causes inhibition of cell survival and proliferation. Of note, pneumonia is common in the patients who are treated with BCRi, observed in $4 \%$ to $17 \%$ of patients. Varughese et al reported the incidence of all invasive infections in 378 patients who received BCRi (ibrutinib), and they found $84 \%$ of infections in the first year of treatment. Of these, $37.2 \%$ and $53.5 \%$ had fungal and bacterial infections, respectively. ${ }^{6}$ Ibrutinib inhibited protein kinases such as BTK, tyrosine-protein kinase Fgr, bone marrow kinase on chromosome $\mathrm{X}$ (BMX), and breast tumor kinase. In patients with BTK inhibition (ibrutinib consumption), the neutrophils lack function against fungal infection. Neutrophils are recruited to sites of fungal inflammation from the bloodstream, and in this stage, cytokines play the main role. Recruiting neutrophils depends on E-selectin receptors. ${ }^{7-9} \mathrm{E}$ - and P-selectins are expressed on endothelial cells, which are affected by inflammation and bind to glycoprotein ligands on neutrophils. E-selectin has the key role in neutrophils' slowrolling on endothelial cells, and they are essential to the fungal infection site. BTK has functions on E-selectin dependent neutrophils' slow-rolling by activation of $\beta 2$-integrins among the PLC $\gamma 2$ and Phosphoinositide 3-kinase (PI3K) pathway. ${ }^{9,10}$ Another role for BTK in neutrophils is inducing the release of granule proteins and reactive oxygen species (ROS). ${ }^{10}$ This activity depends on fungal recognition on $\beta$-glucan and integrin CR3 adhesion molecules. The adhesions trigger the PI3K pathway and the non-oxidative intracellular mechanism of killing. ${ }^{9,10}$

PI3K signaling pathways are considered as a critical component of the immune response regulation; this has lead researchers to focus on this pathway for more investigations profoundly. PI3K pathway activity is correlated with the promotion of cell growth, survival, and resistance to radiotherapy and chemotherapy. The PI3K inhibitors have various applications in the regulation of inflammations and hematologic cancers such as Hodgkin lymphoma and Lymphoid malignancies, but the new generation of these drugs has imposed some unclear side effects. The oral administration of CLR457, pan-PI3K inhibitor, prevents all PI3K kinase isoforms leading to apoptosis and growth inhibition in tumor cells that overexpress PI3K. ${ }^{11,12}$ Also, idelalisib, an inhibitor of PI3K, is approved for the treatment of lymphoma and Chronic lymphocytic leukemia (CLL) in the relapsed/ refractory setting. Administration of other PI3K inhibitors such as Duvelisib, TGR-1202, and PI3K p1108 inhibitor that are developed to target various isoforms of PI3K enzyme result in various toxicities and different efficacies in clinical settings. ${ }^{13,14}$ Furthermore, significant infectious toxicities have been reported in several trails, like opportunistic infections frequently associated with immunocompromised patients. These infections appear in the context of therapy-/ disease-related cytopenias, but it is likely to get influenced by PI3K inhibitors as the mediators of the immune system. ${ }^{14,15}$ Finally, these inhibitors affect the immune system and lead to an immunocompromised immunity in the patients. This prepares the situation for the development of opportunistic organisms to infect people and worsen the patients' condition. Therefore, prophylaxis in hematologic malignancies patients treated with PI3K inhibitors can be helpful in the management of opportunistic fungal infections.

In chronic myelogenous leukemia (CML), the most common malignancy between MPDs, BCR/ABL1 fused protein, which has higher kinase activity, is the most frequent. In the treatment of CML patients with imatinib, a kinase inhibitor was prescribed. Also, dasatinib, a new generation of the imatinib, has the same inhibition effects as the imatinib. In this regard, also, PI3K $\gamma$ pathway was inhibited as the drug side effect. The inhibition of the PI3K $\gamma$ pathway causes defects in the neutrophil slow-rolling, the release of granule proteins, and the production of reactive oxygen species. Another MPDs point mutation (c.1849G $>$ T) in the JAK2 gene, a protein in the JAK2STAT5 signal-transduction pathway, causes the substitution of phenylalanine for valine (V617F) in the protein and has 
been detected in MPNs especially in Polycythemia Rubra Vera (PRV or PV) by $65 \%$ to $97 \%$, Essential Thrombocythemia (ET) (30\%-57\%) and, primary myelofibrosis (35\%-95\%) depending on the detection method. ${ }^{16}$ In the treatment of these patients the AG490 and its analogues are introduced as new drugs for inhibition of mutated and highly activated JAK2V617F. ${ }^{17}$ This can induce the inhibition of STAST5 and proliferation of other myeloid linage, except erythron. This prevention also affects neutrophil counts, and opportunistic syndrome can result in fungal like infections. At the end, using antibiotics in prevention of infection can cause neutropenia or WBC malfunction. ${ }^{18}$ So, patients with blood malignancy who were treated by BMT, chemotherapy, target therapy, and antibiotics are more susceptible to opportunistic infections, especially fungal infections, because of the suppression of the immune system. In this review, we have considered the different dimensions of the most important IFI such as aspergillosis, candidiasis, fusariosis, cryptococcosis, trichosporonosis, and mucormycosis in patients with blood malignancy and present a complete list of these infections with different clinical manifestations, treatment, and outcomes.

\section{Immune System, Blood Malignancies, and Fungal Infection}

The innate immune system of the body plays a crucial role in the regulation of host-fungi interaction. It protects the body against fungal infection by killing the fungal agent directly, modulating the microbial communities that affect fungal commensalism, and polarizing adaptive immune systems such as the polarization of Th1 and Th17. These host functions are accomplished through recognition of receptors of fungal determinants and sensing geometric signs (eg, size of the fungi). ${ }^{19}$ Fungal ligands trigger a range of pattern recognition receptors (PRRs) like C-type lectin receptors (CLRs), NOD-like receptors, and Toll-like receptors (TLRs). Particularly, myeloid cells that identify fungal cell wall polysaccharides express some CLRs. Consequently, CLRs activate signaling pathways and cellular responses. As the primary phagocytes of the innate immune system, neutrophils express CLRs and produce reactive oxygen species (ROS) and facilitate host defense. ${ }^{20,21}$ Deficiencies in the function of phagocyte NADPH oxidase (PHOX) result in chronic granulomatous disease (CGD). This disease is mostly characterized by the susceptibility of the host to get infected by invasive infections, including those by the generally non-pathogenic fungus Aspergillus nidulans. In immunocompetent individual fungal infections are usually harmless; nonetheless, susceptibility to the invasive infections in people with inherited immunodeficiency and patients treated with immunosuppressive medications that weaken the innate immune cell function, particularly patients with neutropenia, is considerably high. ${ }^{22}$

As mentioned, all blood malignancies engage the immune system and raise the chances of IFIs. There are some reasons for such susceptibility, including $\mathrm{T}$ cell (cellmediated immunity) dysfunction, hypogammaglobinemia (humoral immunity), neutropenia caused by bone marrow involvement, and leukopenia due to chemotherapy or BMT. $^{3,23}$ Primarily, neutrophils are responsible for destroying hyphae post-germination, while in immunocompetent hosts, macrophages, and neutrophils both can inhibit germination or kill conidia. This is an essential response to fungal infection. Innate immunity plays a key role in the lung by Alveolar macrophage. Recent studies have suggested that alveolar macrophages identify and perform phagocytosis in various fungal species through attachment to dectin-1. Therefore, myeloid linage has the leading role in innate immunity and also in the second adaptive immune response against IFIs. In patients with blood malignancies, the WBCs decrease, and this leads to susceptibility to IFIs. ${ }^{24,25}$ Infections mostly occur in patients with absolute neutrophil count (ANC) of $<500 / \mathrm{mm}^{3}$, and those with the ANC of $<100 / \mathrm{mm}^{3}$ are at a higher risk. ${ }^{26}$ Studies show that severe and prolonged neutropenia rises susceptibility to fungal infection. Furthermore, in AML, maturation arrest results in a decrease in the mature neutrophil count; also, the mature neutrophils present in the peripheral blood of these patients may be dysfunctional. Therefore, the ANC in AML patients may mislead the physician in estimating the risk of IFIs. $^{26-29}$ The ANC and function of neutrophils are regarded as a part of the innate immune system.

The lymphocytic leukemia is characterized by a deficiency in lymphocyte production and trafficking, and alterations in lymph organ function. Changing the lymphocyte function is related to the adaptive immune system. Noteworthy, this part of the immunity is the second line opposing IFIs like cryptococcosis. $^{30}$ In CLL, deficiency in innate immunity mostly includes hypocomplementemia, and dysfunctional neutrophils and NK cells. This can lead to a disrupted antibody function through CD20- targeting and complementdependent cytotoxicity. ${ }^{31,32}$ Moreover, deficiencies in the adaptive immune responses in CLL involve a decrease in CD4: CD8 ratio, a rise in immunosuppressive FoxP3+ 
regulatory $\mathrm{T}$ Cells, and helper $\mathrm{T}$-cell impairment. ${ }^{31,33}$ Consequently, a compromised innate and adaptive immunity in lymphocytic leukemia results in a higher risk of IFIs.

\section{Aspergillosis}

Aspergillosis can be categorized in many forms, such as invasive, chronic, saprophytic, and allergic. ${ }^{34}$ Aspergillosis is a major concern for the healthcare system and scientific communities since they cause deadly diseases in patients with blood malignancies. ${ }^{35,36}$ Aspergillus species specifically cause infections in the respiratory and gastrointestinal tract and skin. However, various clinical manifestations have been reported in patients with hematologic malignancies that some of them are listed in Table $1 .{ }^{37}$ In previous studies, Aspergillus species such as A. fumigatus, A. flavus, $A$. terreus, and $A$. niger, were reported to be the most common pathogenic agent in patients. ${ }^{36,38}$ In the intensive care unit (ICU), fungal infection is a major issue, and in vulnerable patients, it increases the morbidity and mortality rates. The IFI challenge in neutropenic patients is high, but in non-neutropenic individuals, the risk of IFI remains. The most common infections in the ICU are aspergillosis, candidiasis, and mucormycosis. ${ }^{39}$ In non-neutropenic individuals and patients admitted to the ICU even with no signs of classic predisposing immunodeficiency, the emergence of aspergillosis has been identified increasingly. The invasive aspergillosis occurrence in ICU has been reported in ranges from $0.3 \%$ to $5.8 \%$, with an overall mortality rate of $>80 \% .^{39-43}$ Moreover, in the other patients with blood or lymphoid tissue malignancies, liver, and bone marrow transplant recipients, the mortality rate related to the aspergillosis is reported $49 \%, 90 \%$, and $80 \%$, respectively. ${ }^{39,44}$

The incidence of invasive aspergillosis among patients with leukemia is estimated as high as $12.7 \%$, and the most important factors causing invasive aspergillosis in patients with hematologic malignancies are mucosal damage, prolonged and profound neutropenia, and immunosuppressive drugs that make a patient susceptible to this infection. ${ }^{45,46}$ Furthermore, hematopoietic stem cell transplantation is also prone to aspergillosis due to some factors such as the development of graft-versus-host disease, expansion of human leukocyte antigen (HLA) discordance, and the presence of respiratory virus co-infection or cytomegalovirus (CMV). ${ }^{35,46-48}$ Therefore, because of the high risk of aspergillosis in these patients, prophylaxis with drugs such as caspofungin, micafungin, voriconazole, posaconazole, liposomal amphotericin B (LAMB), and caspofungin may be beneficial. $^{48-50}$ Noteworthy, depending on the patient's condition, these drugs can have different effects; however, side effects and toxicity of these drugs may limit their longterm use. $^{51}$ Fontana and his colleagues reported that, although isavuconazole was used for prophylaxis patients with hematologic malignancies or hematopoietic cell transplant recipients to prevent IFI, the results showed an increase in the rate of IFI, especially invasive pulmonary aspergillosis in these patients. ${ }^{52}$ Therefore, it seems that using drugs alone to prevent invasive aspergillosis in patients with hematologic malignancies may not be sufficient and cause further difficulties. Thus, creating a protective environment for patients along with prophylaxis can be helpful. In this regard, regulating room ventilation, appropriate room sealing, and the application of high-efficiency particulate air (HEPA) filters can be noted. ${ }^{53,54}$ For example, the results of one study showed that posaconazole prophylaxis in patients with AML, along with HEPA filtration, can be useful in preventing invasive aspergillosis during hospital building works. ${ }^{55}$

In addition to prophylaxis, the use of diagnostic methods that quickly detect fungal disease is also very effective in the treatment of the patient with blood malignancy. Previous studies have suggested that using different diagnostic methods such as $\beta$-D-glucan assays, Aspergillus galactomannan enzyme-linked immunosorbent assay (EIA), and a combined monitoring strategy based on serum galactomannan and polymerase chain reaction (PCR)-based detection of serum Aspergillus DNA are useful strategies for early diagnosis and lower incidence of invasive aspergillosis in high-risk hematological patients, because these methods can quickly detect invasive aspergillosis and determine the patient's treatment strategy. ${ }^{45,56-59}$ Lateral flow assays for invasive aspergillosis offer the potential for rapid diagnosis, ease of performance, and point of care use. A murine monoclonal antibody attaches to an extracellular glycoprotein antigen that only releases during the active growth of Aspergillus hyphae. This antigen particularly secretes from Aspergillus hyphae, not conidia; therefore, this method also differentiates between hyphae and conidia. ${ }^{60}$ In a study, Eigl et al reported that lateral-flow device (LFD) tests on the bronchoalveolar lavage (BAL) samples of ICU patients is a promising method in the diagnosis of invasive pulmonary aspergillosis (IPA). Since this test can be handled easily and enables rapid results; therefore, once the galactomannan test is not available, the LFD test could be a potential alternative for IPA diagnosis in ICU patients. ${ }^{61}$ Also, the results of another study showed that Aspergillus LFD seems to be a promising alternative to galactomannan testing, ${ }^{62}$ and its speed and accuracy provide a novel adjunct point-of-care test for diagnosis of IPA in 


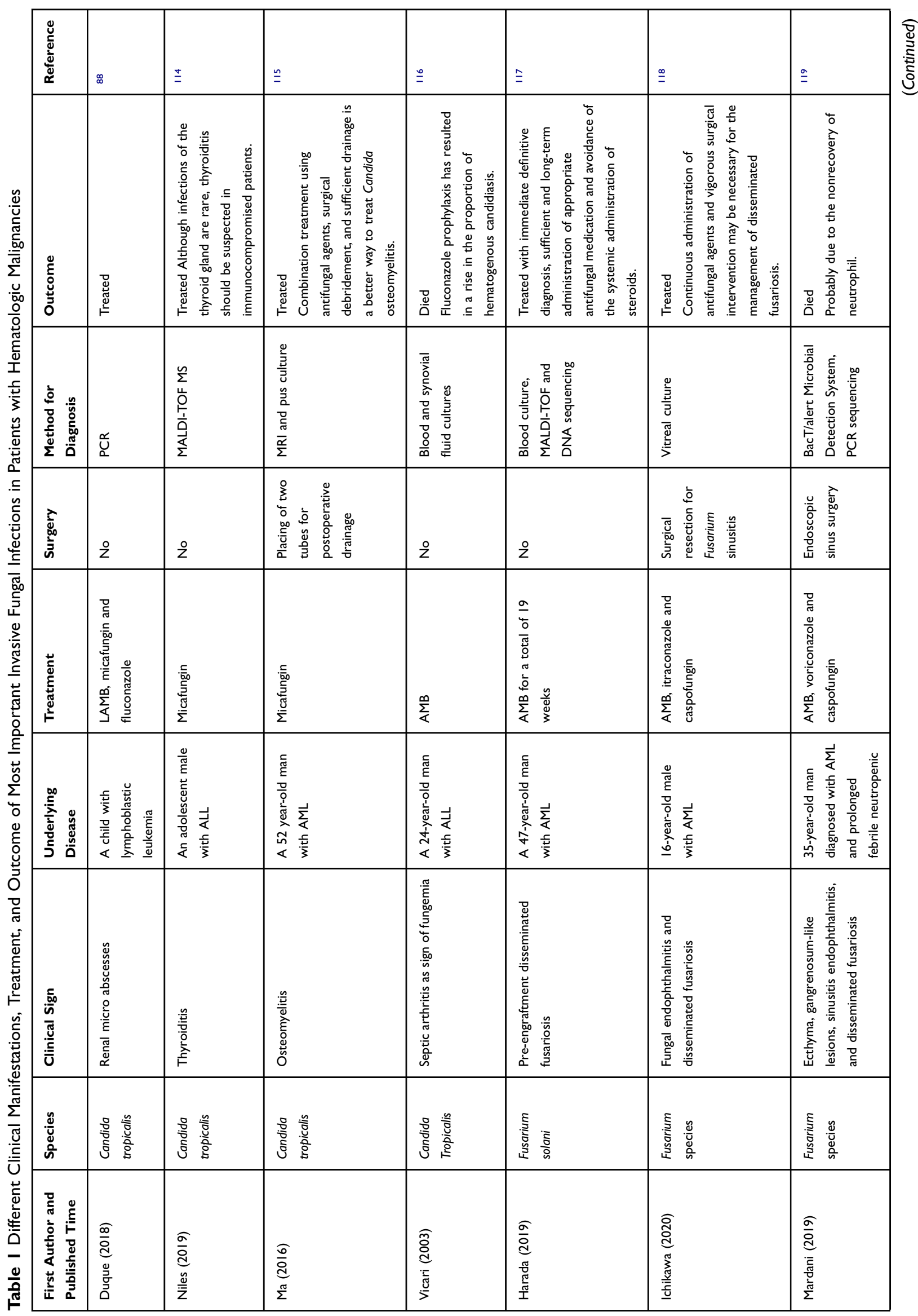




\begin{tabular}{|c|c|c|c|c|c|c|c|}
\hline 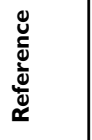 & $\stackrel{̊}{\Omega}$ & $\overline{\underline{a}}$ & $\underline{\Xi}$ & $\cong$ & \pm & 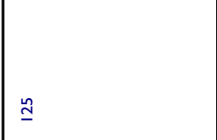 & $\cong$ \\
\hline 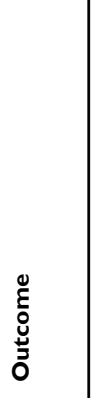 & 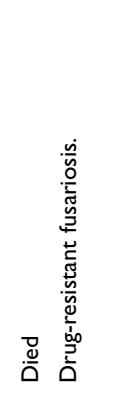 & 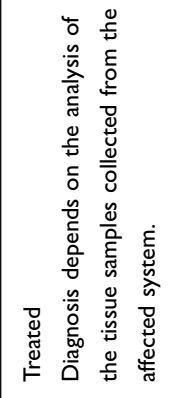 & 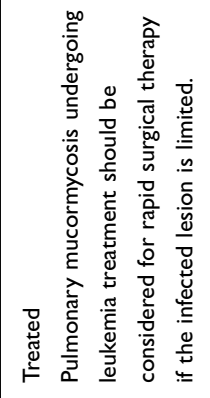 & 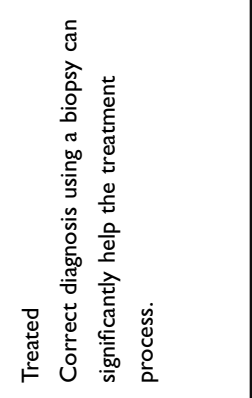 & 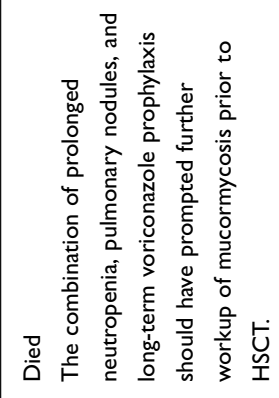 & 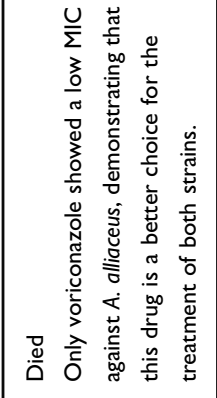 & 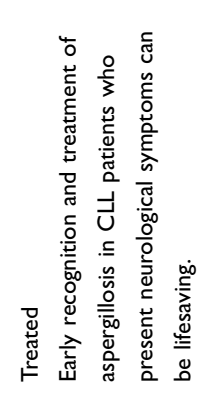 \\
\hline 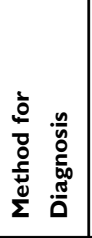 & 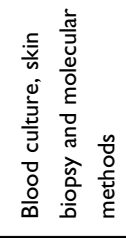 & 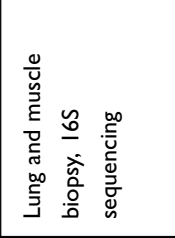 & 岌 & 岌 & 岌 & 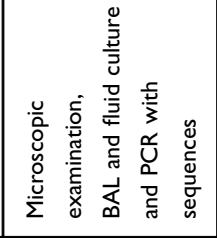 & 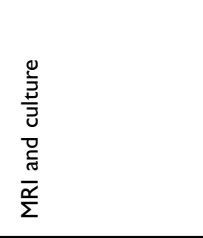 \\
\hline 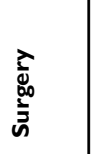 & $\stackrel{\circ}{z}$ & 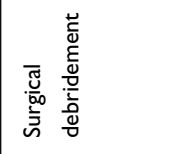 & 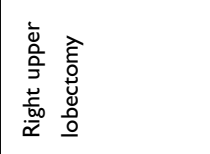 & 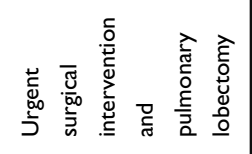 & z & z & 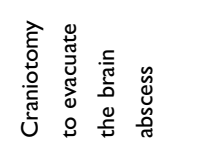 \\
\hline 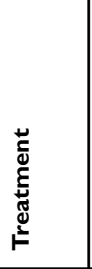 & 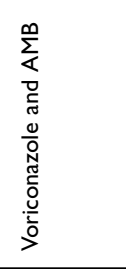 & 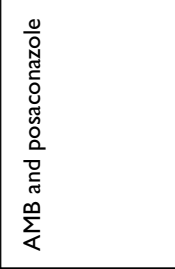 & $\sum_{<}^{\infty}$ & 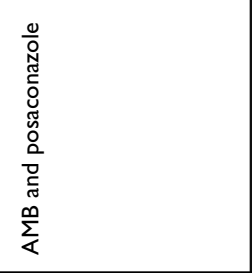 & 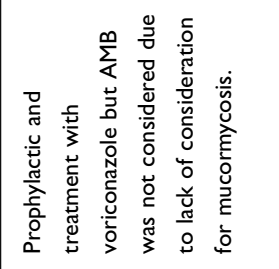 & 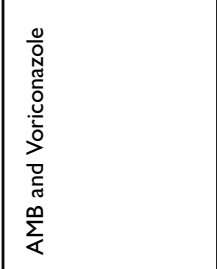 & 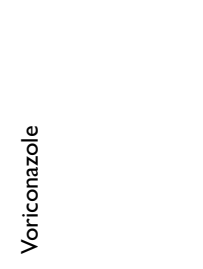 \\
\hline 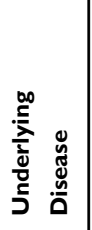 & 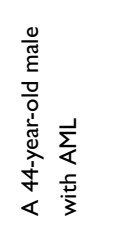 & 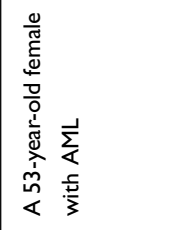 & 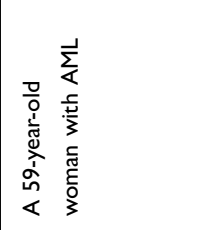 & 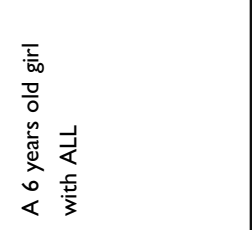 & 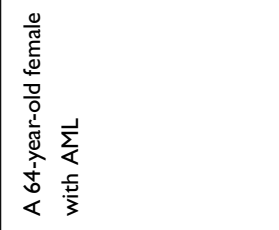 & 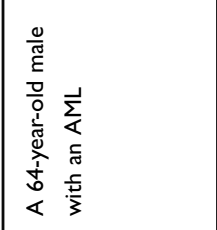 & 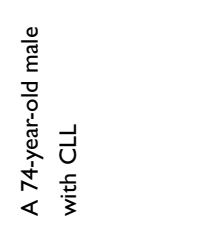 \\
\hline 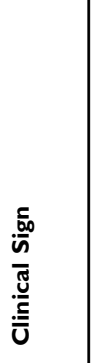 & 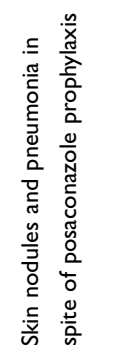 & 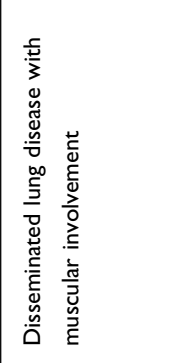 & 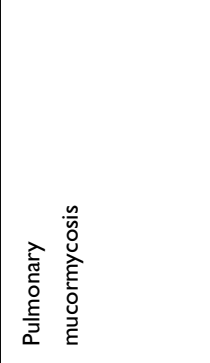 & 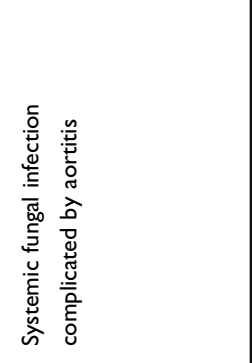 & 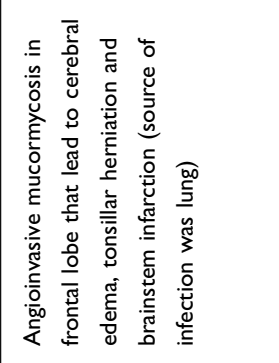 & 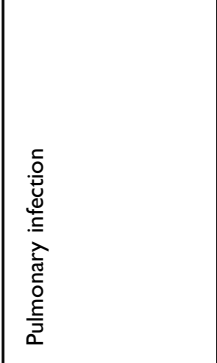 & 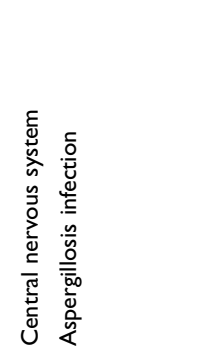 \\
\hline 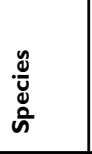 & 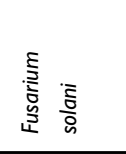 & 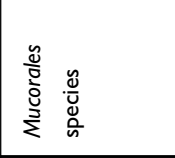 & 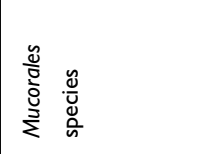 & 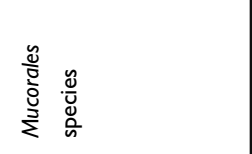 & 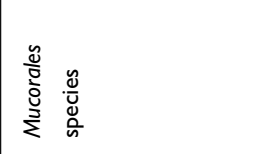 & 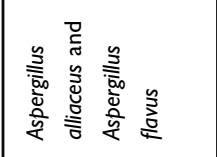 & 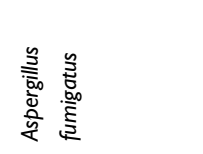 \\
\hline 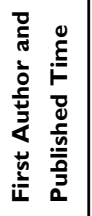 & 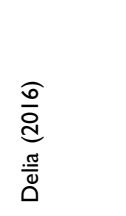 & 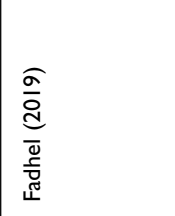 & 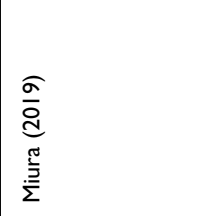 & 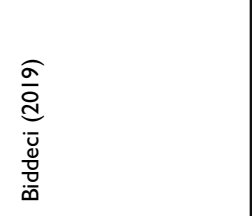 & 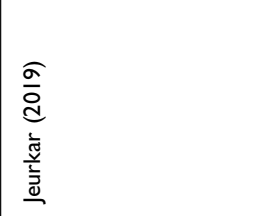 & 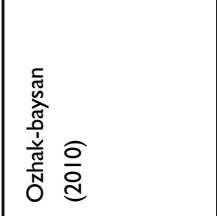 & 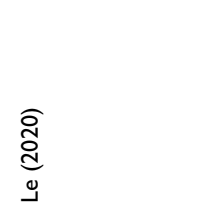 \\
\hline
\end{tabular}




\begin{tabular}{|c|c|c|c|c|c|c|}
\hline$\cong$ & $\stackrel{\infty}{\Xi}$ & $\cong$ & $\stackrel{\circ}{\underline{m}}$ & $\approx$ & $\overline{\underline{m}}$ & $\underline{\underline{m}}$ \\
\hline 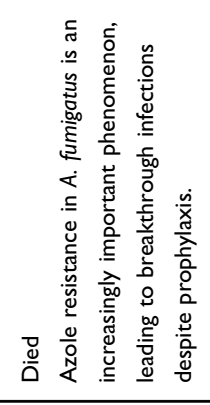 & 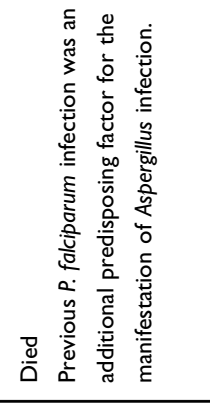 & 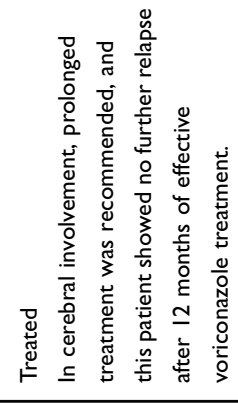 & 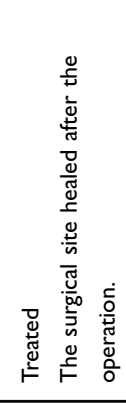 & 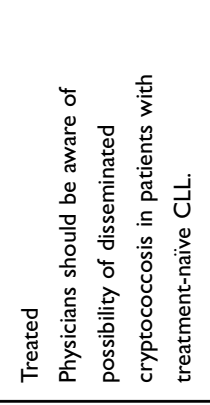 & 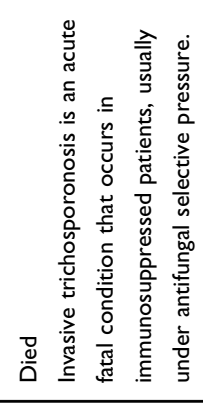 & 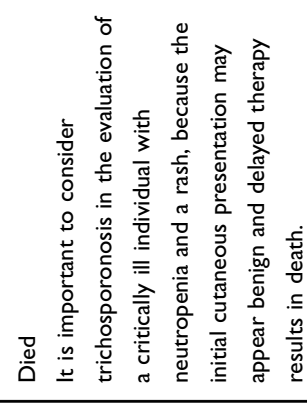 \\
\hline 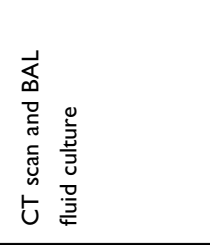 & 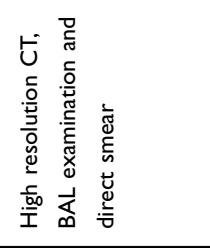 & 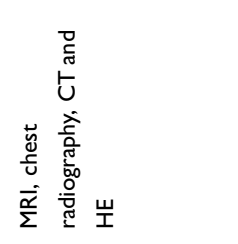 & 포 & 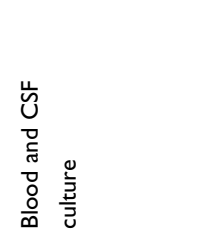 & 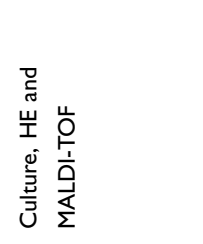 & $\frac{0}{\overline{3}}$ \\
\hline z & $\stackrel{\circ}{z}$ & $\stackrel{\circ}{z}$ & 产 & o & $\stackrel{\mathrm{O}}{\mathrm{z}}$ & ㅇ \\
\hline 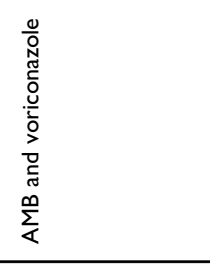 & $\sum_{<}^{\infty}$ & 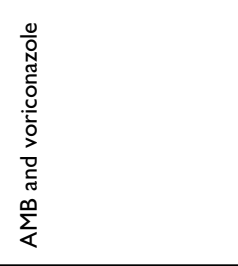 & 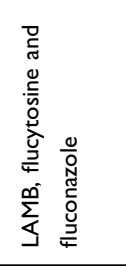 & 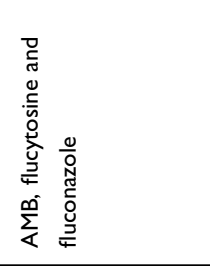 & 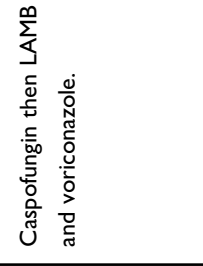 & 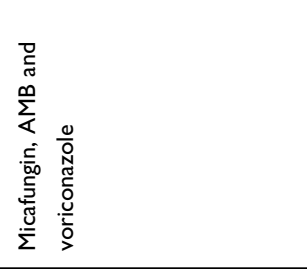 \\
\hline 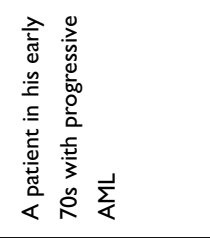 & 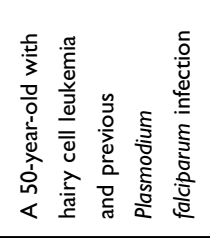 & 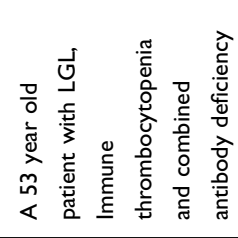 & 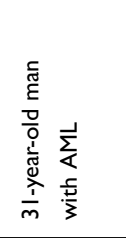 & 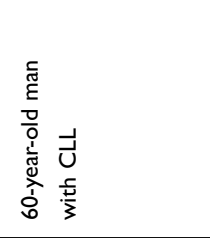 & 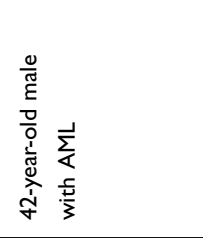 & 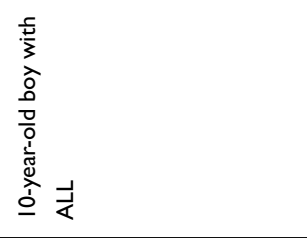 \\
\hline 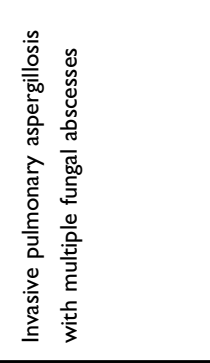 & 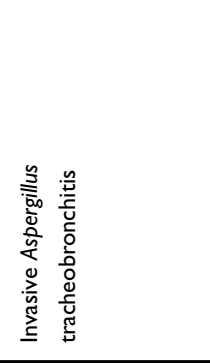 & 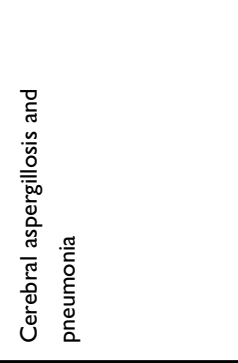 & 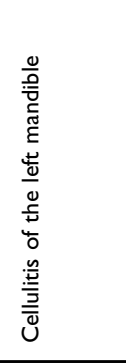 & 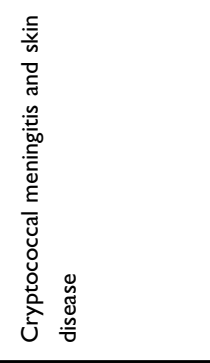 & 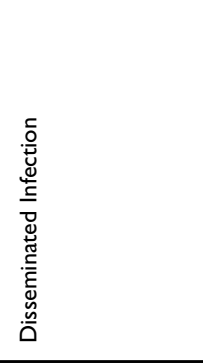 & 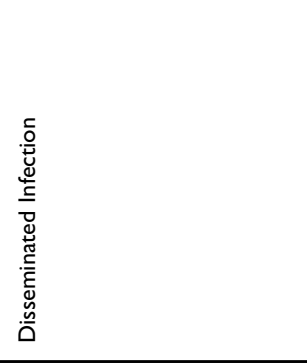 \\
\hline 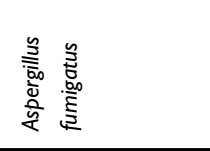 & 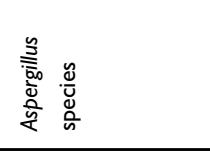 & 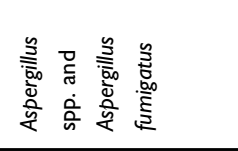 & 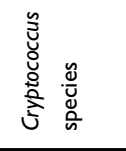 & 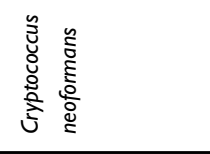 & 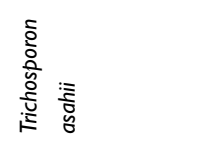 & 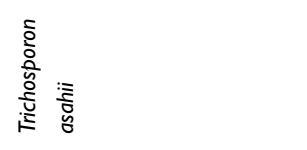 \\
\hline 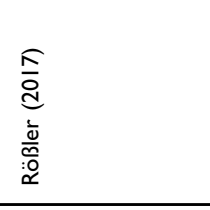 & 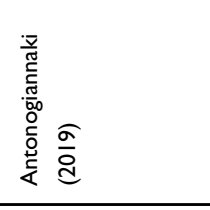 & 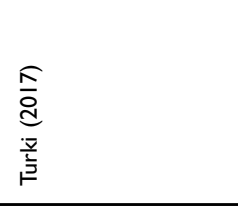 & 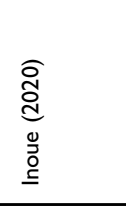 & 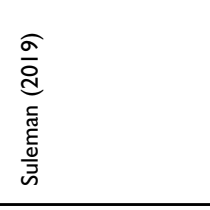 & 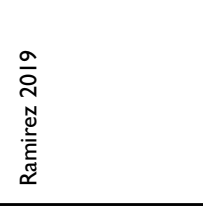 & 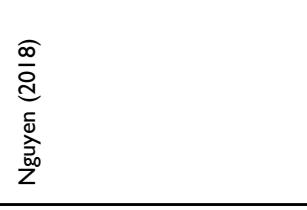 \\
\hline
\end{tabular}


patients with blood malignancies. ${ }^{63}$ A 7 -study meta-analysis reported that the sensitivity and specificity of the Aspergillus LFD on the serum specimens for the identification of proven or possible cases of invasive aspergillosis is $68 \%$ and $87 \%$, respectively. ${ }^{64}$ Also, in another study, a specificity of $98.0 \%$ and a sensitivity of $81.8 \%$ was reported for LFD. Along with PCR, the LFD enables $100 \%$ sensitivity and specificity. The outcomes of this study suggest that developing an LFD assay that targets a unique biomarker is a promising and straightforward diagnostic method that provides excellent clinical performance, especially in combination with PCR. ${ }^{65}$ So, although LFD commercial availability is still pending in the United States, in different studies, the test has shown excellent performance and results; this suggests a feasible alternative to the Aspergillus Galactomannan EIA. Finally, it should be noted that a monoclonal antibody 476-based LFD for point-of-care diagnosis of urinary excreted fungal galactomannan like antigens has been developed but needs further validation. ${ }^{66}$

Drugs such as voriconazole and LAMB are used to treat infections caused by Aspergillus species, also other new drugs such as anidulafungin and isavuconazole are considered to be used widespreadly but this requires further studies. ${ }^{54,67,68}$ For example, the results of a recent study showed that prophylaxis with isavuconazole is not effective in preventing invasive Aspergillus infections, and further studies are needed to use this drug widely. ${ }^{52}$ Furthermore, drug resistance is a critical issue in Aspergillus species. A. calidoustus and A. terreus can be inherently resistant to azoles and AMB, and A. fumigatus can also be resistant to azoles. ${ }^{69-71}$ Noteworthy, the incidence of invasive aspergillosis caused by azole-resistant A. fumigatus is increasing in patients with hematologic malignancies. ${ }^{72}$ One study reported that azole-resistant A. fumigatus, despite treatment with isavuconazole, caused the death of two AML patients, and this indicates the importance of drug-resistant Aspergillus species and the need for rapid detection of these isolates. ${ }^{73}$ Non-culture based molecular methods such as conventional PCR assays and a quantitative assay detecting a singlenucleotide polymorphism can help diagnose drug resistance in Aspergillus species, effectively. ${ }^{72,74}$ Therefore, drug resistance in aspergillosis can increase mortality, and if resistance is detected or suspected, changing the treatment line or drug combinations can be a useful strategy for a better control of the infection. In addition to the therapeutic role of different drugs, other strategies are used to control different Aspergillus infections in patient with blood malignancy. Dong and his colleagues reported that surgical resection of focal invasive pulmonary aspergillosis can be a safe and applicable treatment in patients with fatal hemoptysis risk, also, long-term treatment with ineffective antifungal medications may interfere life-saving cancer chemotherapy. ${ }^{75}$ On the other hand, another study found that despite the extended surgery and antifungal therapy for ALL patient with infection of the gastro intestinal tract by Aspergillus species, the outcome of disseminated invasive aspergillosis with intestinal involvement remains poor. ${ }^{76}$ So, surgery is not applicable to patients with leukemia with unstable conditions and disseminated infection and the use of surgery should be tailored to the patient's condition. ${ }^{36,54}$ In addition, some new immunotherapy strategies such as colony-stimulating factors, granulocyte transfusions, recombinant interferon gamma and adoptive transfer of pathogen-specific $\mathrm{T}$ lymphocytes can be used to control invasive aspergillosis and improve outcome in patients with leukemia, although widespread use of these methods needs further study. ${ }^{46,48,54,77,78}$

Therefore, infections caused by Aspergillus species are very dangerous and deadly in patients with leukemia. Prophylaxis, early diagnosis, appropriate drug treatment, and providing a safe environment for patients (Figure 1) can help control invasive aspergillosis. Furthermore, drug resistance in Aspergillus species is essential, and inappropriate use of drugs can easily cause death in patients with blood malignancy. Thus, an accurate diagnostic approach is necessary for selecting a better treatment line.

\section{Candidiasis}

Candida species are one of the most frequent isolated nosocomial agents that can involve various organs, particularly eyes, liver, kidney, and brain in patients with hematological malignancies such as acute leukemia, lymphoma, and myelodysplastic syndrome. ${ }^{79}$ The most common members of this species that are capable of infecting humans are C. albicans, C. glabrata, C. tropicalis, C. parapsilosis, and C. krusei. ${ }^{80}$ Recently, studies have reported that within ICU patients with invasive candidiasis, candidemia will develop in two-thirds of the patients, and $80 \%$ of non-candidemia patients will develop intraabdominal candidiasis. It has been documented that candiduria occurs in almost $20 \%$ of ICU patients, although associated tissue infection or secondary candidemia occurs in less than $5 \%$ of them. ${ }^{81-84}$

In patients with blood malignancies that undergo remission-induction chemotherapy for AML or myelodysplastic 


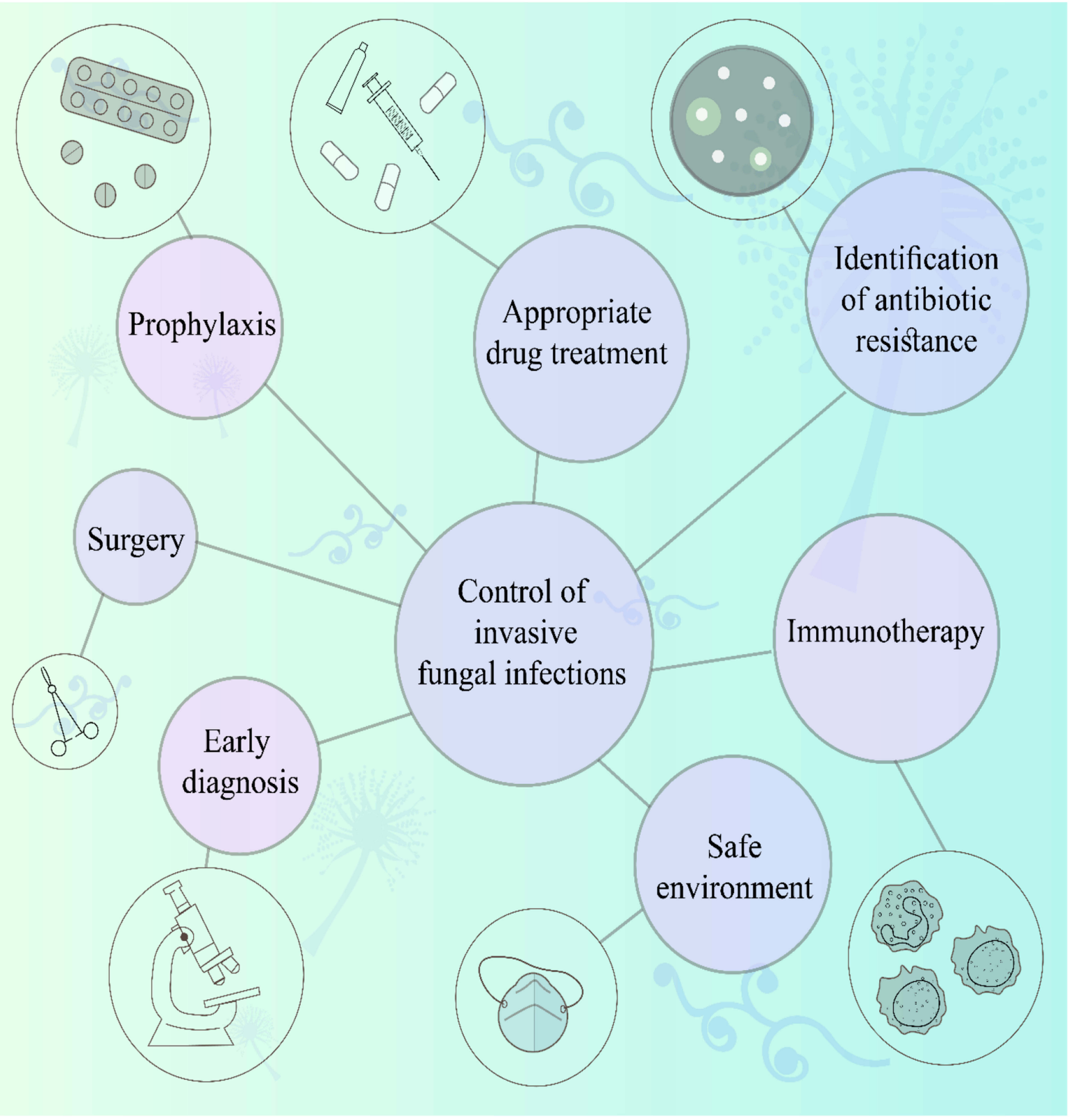

Figure I Strategies for controlling invasive fungal infections in patients with hematologic malignancies.

syndrome and the recipients of allogeneic hematopoietic stem cell transplants, the chance of infection by these microorganisms is increased because of the disorders in the immune system of the body especially a sharp decrease in the number of neutrophils. Also in these patients, the mucus is usually damaged, which can lead to the increased growth of the Candida species, and the chances of entering the blood and causing candidemia. ${ }^{85,86}$ In different studies, different species of Candida have been identified pathogenic in patients with varying types of leukemia. ${ }^{87,88}$ The source of infections in people with Candida is usually endogenous because it is present in the body as normal flora, and proper prophylaxis can help controlling it. ${ }^{89}$ A study in China after a seven-year experience reported that $C$. tropicalis is the most common cause of candidemia among patients with acute leukemia, and the vast majority of these infections are endogenous. The results of this study showed that empiric antifungal treatment before the first positive culture helps patients to survive, and utilizing prophylaxis new drugs, including voriconazole and posaconazole, may result in a decreased candidemia incidence and a better chance of cure and survival. ${ }^{90,91}$ Furthermore, Candida species such as $C$. albicans and C. glabrata can overgrow in the mouth of people with leukemia. Once it becomes systemic, it is hard to 
diagnose, control, and treat the disease in such patients. Therefore, controlling oral infections in these patients can be very effective in hindering aggressive infections caused by Candida species. ${ }^{92}$ In children with hematologic malignancies due to persistent febrile neutropenia, candidiasis can lead to high mortality and lack of prophylaxis can worsen the prognosis. A recent study reported that abnormal chest x-ray and clinical sinusitis are important predictors of invasive candidiasis in these patients, and protocols that include early empirical antifungal therapy covering this infection is essential. ${ }^{93}$ Thus, as noted, prophylaxis may be effective in reducing the rate of disseminated candidiasis in people with leukemia, but long-term use of antifungal drugs may impose some difficulties, and the results of some studies have shown that despite prophylaxis, IFI has occurred in patients with blood malignancies.

One study reported that long-term use of voriconazole can lead to serious complications such as actinic keratosis, squamous cell carcinoma, and skeletal fluorosis, and another study reported that administration of this drug leads to hallucinations, visual changes, and photosensitivity in patients. ${ }^{94,95}$ Furthermore, Casero et al reported that prophylaxis was less effective in patients with acute leukemia after allogeneic stem cell transplantation, and the risk of candidemia was high in these patients. ${ }^{96}$ It should be noted that in some patients with hematologic malignancies, despite drug prophylaxis, disseminated infections with Candida species may occur as a consequence of drug resistance in this microorganism. ${ }^{97}$ You and his colleagues reported that $C$. tropicalis that caused disseminated candidiasis in a patient with ALL resulted in death when posaconazole was used as a prophylactic drug. The results of this study showed that enhanced efflux pumps and changes in the azole target enzyme Erg11p, caused $C$. tropicalis resistance to azoles, and infection with this microorganism may lead to a longer period of hospitalization, administration of more expensive/toxic drugs, and a higher rate of mortality. ${ }^{98}$ Noteworthy, the candidiasis appears with different clinical manifestations in patients with hematological malignancies and it is difficult to detect this microorganism due to the absence of specific symptoms (Table 1).

Rapid detection of candidiasis is necessary to control infection and reduce mortality. Methods used to diagnose candidiasis include blood culture and serological tests to detect $\beta$-D-glucan. ${ }^{88,89}$ In addition, molecular methods, such as PCR-RFLP, Real-time PCR Fluorescence Resonance Energy Transfer probe assay and T2 Magnetic Resonance (T2MR), can help to control the chronic disseminated candidiasis as they allow rapid identification of the Candida species. ${ }^{99-101}$ T2MR-based biosensing is able to detect different targets within complex matrices such as blood. This method needs a specific instrument and identifies Candida species in the blood samples directly; however, unlike the blood cultures, viable organisms are not essential in this method. ${ }^{60} \mathrm{~T} 2 \mathrm{MR}$ is a qualitative molecular diagnostic method approved by the FDA. In this method, PCR molecular assay and nuclear magnetic resonance are joined to identify the five most frequent Candida species, including C. tropicalis, C. glabrata, C. krusei, C. albicans, and C. parapsilosis in approximately $5 \mathrm{~h} .{ }^{102,103}$ The results of a recent study showed that T2MR with clinical sensitivity of $89 \%$ can diagnose candidemia at the time of positive blood cultures. Furthermore, this test could diagnose infected patients with negative blood cultures who had received antifungal therapy before their tests. ${ }^{104}$ Furthermore, specificity $76.1 \%$ and sensitivity $100 \%$ was reported for T2MR in another study, and these results suggested that this test may be a better marker of complicated infection than follow-up blood cultures or blood $\beta$-d-glucan ${ }^{105}$. Also, Mylonakis et al reported overall sensitivity $91 \%$ and specificity $98 \%$ with a mean time of $4.4 \pm 1.0$ hours for diagnosing and identifying species using the T2MR method. ${ }^{103}$ Therefore, T2MR is a novel and fully automated technology to analyze whole blood specimens to diagnose the Candida species without preceding isolations. This test represents a step forward in the new era of molecular diagnosis. On the other hand, the T2MR has some limitations; for example, the test can detect only five species of Candida, the reliability of the test has not examined in the deep-seated candidiasis, and the data to assess the performance of the T2MR in invasive candidiasis without candidemia is not sufficient. ${ }^{102}$ Thus, more studies are required to shed light on further implications of T2MR in medical settings for the diagnosis of such infections.

Another microorganism identification tool, matrix assisted laser desorption ionization-time of flight (MALDITOF) mass spectrometry, is a novel technology that detects bacteria, and most recently, yeast, within minutes with reliable results than the conventional methods. ${ }^{107-110}$ Many laboratories are equipped with this instrument due to its high simplicity and reliability. ${ }^{108-111}$ Some researchers believe that mass spectrometry could substitute the microscopy identification method as the first-line detection of microorganisms isolated from patients' specimen cultures. ${ }^{109,112,113}$ Noteworthy, Niles et al detected disseminated candidiasis in males with ALL using MALDI-TOF mass spectrometry. Peripheral blood cultures from admission 
grew budding yeast at 22 hours of incubation, and the yeast was ultimately speciated as $C$. tropicalis by MALDI-TOF mass spectrometry. ${ }^{114}$ The identification of fungal species is essential since many isolates show different susceptibility profiles opposing common antifungal agents, and MALDITOF mass spectrometry is a beneficial method because it needs low sample volumes, and it has rapid turnover time and accuracy in identifying fungal infection at the species and subspecies level. However, this technology requires further developments to be adapted for recognizing all microorganisms grown in biological samples, and the performance of this technology can significantly boost when its database upgrades with more spectra of appropriate reference strains. ${ }^{109,110}$

Therefore, Candida species cause different infections in patients with leukemia, and given the endogenous nature of this microorganism, prophylaxis may be efficient in reducing mortality although long-term use of the drugs may lead to toxicity and results in different outcomes in patients with different conditions. Finally, the non-culturebased tests can be performed with each other to increase the detection of invasive candidiasis, significantly, to establishing an early diagnosis of infection.

\section{Mucormycosis}

Aspergillosis and Candidiasis cause dangerous fungal diseases in people with blood malignancies. However, mucormycosis causes in pediatric oncology patients. ${ }^{122,133}$ Mucormycosis is a dangerous progressive disease caused by the filamentous fungi of the Mucorales order of the class of Zygomycetes. ${ }^{134}$ The order Mucorales consist of varieties of species such as Mucor, Saksenaea, Syncephalastrum, Cunninghamella, Rhizopus, Absidia, Rhizomucor, and Apophysomyces that are involved in human diseases most frequently. ${ }^{135}$ These microorganisms are mostly opportunistic and produce much airborne spore, and usually, they are not problematic in people with normal immunity, although they can cause aggressive, malignant and lethal infection in patients with underlying diseases such as solidorgan malignancies, chronic renal failure, malnutrition children, immunocompromising conditions and diabetes mellitus. ${ }^{136-139}$ Mucormycosis in ICU patients is mostly related to massive injuries, including natural disasters or complex combat trauma and motor vehicle accidents. ${ }^{140-143}$ A comprehensive epidemiologic data related to the mucormycosis in the ICU is not available, but frequent cases of mucormycosis have been reported by individuals or small series in ICUs. ${ }^{39,144-146}$
Also, patients with hematologic malignancies are highly susceptible to mucormycosis due to abnormalities in their immune systems. In severe neutropenia, a poor prognosis can lead to a 75 to $80 \%$ mortality rate, and delay in initiating treatment for these patients is hazardous and fatal. ${ }^{138,147}$ Mucormycosis can present a localized or disseminated form of infection, and lung is the most prevalent site of infection in patients with blood malignancies, although other organs such as the paranasal sinuses, skin, brain, and gastrointestinal tract can also be involved. ${ }^{148-150}$ In patients with low levels of immunity, mucormycosis develops as a deadly disease, whereas cutaneous disease is rarely disseminated and is associated with better outcomes. ${ }^{151}$ Noteworthy, people with a healthy immune system can also get involved with Mucorales (the genera Apophysomyces and Saksenaea); this situation is observed in patients with severe burns and penetrating trauma. ${ }^{152}$

Several principles work together to prevent and treat mucormycosis in patients with hematologic malignancies. The first line of treatment for mucormycosis is the use of AMB; the application of this drug in combination with some triazoles, such as posaconazole and isavuconazole, can improve its efficacy. ${ }^{136}$ It should be noted that other members of the triazoles family, such as itraconazole, voriconazole, and fluconazole, have a minimal inhibitory effect on the Mucorales, and they are not recommended for the therapeutic purposes. ${ }^{153,154}$ Also, combination therapy, including AMB with echinocandins or posaconazole, can be helpful. ${ }^{155,156}$ Nevertheless, the results of previous studies on the use of combination therapy for different patients have been conflicting. For example, combination therapy with AMB and echinocandins has been beneficial in diabetic patients with rhino-cerebral mucormycosis, whereas the same combination treatment has not been successful in patients with blood malignancies. ${ }^{157}$ Therefore, further studies are required to determine the performance of combination therapies in patients with different conditions. Along with the mentioned treatments, it is important to control the patient's underlying conditions, which can assist the treatment process. For instance, controlling diabetes, malnutrition and discontinuing immunosuppressive drugs, if possible, can help control mucormycosis. ${ }^{158}$ Granulocyte colony-stimulating factor (G-CSF), granulocyte (macrophage) colony-stimulating factor (GM-CSF), and interferon- $\gamma$ (IFN- $\gamma$ ) can be used to treat mucormycosis in patients with blood malignancy with deep neutropenia. ${ }^{159,160}$ These compounds increase phagocytosis, oxidative burst, and ultimately enhance the 
antifungal function of neutrophils. Furthermore, IFN- $\gamma$ stimulates T-helper cell type 1 (Th1) immunological response, which increases the body's resistance to IFI. ${ }^{161,162}$ On the other hand, immunotherapy can cause side effects and inflammation in different organs such as inflammatory lung injury, and further studies are needed for widespread use of them. ${ }^{163}$ Surgery can also be helpful to treat mucormycosis depending on the condition of the patient because in some cases mucormycosis causes extensive thrombosis, tissue infarction, and necrosis, this process prevents the penetration of antifungal drugs, so surgery can help control the infection and inhibit its spread. ${ }^{158}$ Surgical debridement in patients with soft tissue infection, localized pulmonary lesion and rhino-orbitocerebral disease can be beneficial, while in patients with disseminated mucormycosis this strategy is not applicable and should be used according to the patient's condition. $^{122,164-168}$ Delay in initiation of mucormycosis treatment in patients with hematologic malignancies results in an increased mortality rate, which requires proper and reliable diagnosis.

Reliable and accurate diagnosis of mucormycosis is a major challenge, since despite aspergillosis, antigenbased detection methods or other standardized serological methods cannot be used to identify mucormycosis. ${ }^{164}$ Culturing method has great limitations and it has been reported that tissue sections are the best samples to be cultured. $^{169}$ Blood cultures are usually negative and the positive cases may indicate contamination. ${ }^{158}$ Histological examination of the tissues sections obtained from surgery can reveal features such as tissue necrosis, angiogenesis, and ribbon-like hyphae. ${ }^{138}$ Although histologic examination has been suggested as the gold standard for the diagnosis of mucormycosis, this method has some limitations for the diagnosis of infection in patients with hematologic malignancies. In these patients, due to severe thrombocytopenia, it is difficult to obtain tissue biopsies, and other biological specimens such as sputum should be used for diagnosis. ${ }^{170,171}$ Noteworthy, molecular methods such as PCR sequencing and Real-time PCR have been used to detect mucormycosis, but little is known about their efficacy. ${ }^{172-175}$ In patients with blood malignancies, the lungs and central nervous system are more infected with Mucorales, and evaluation of the efficacy of molecular methods to detect this microorganism in BAL and cerebrospinal fluid (CSF) samples are needed. ${ }^{176}$

According to the issues discussed earlier, rapid diagnosis, multidisciplinary approach and appropriate treatment to inhibit mucormycosis in patients with hematologic malignancies can reduce the mortality rate of these infections. It should be noted that inhalation and ingestion of sporangiospores is the most common route of mucormycosis transmission, so preparing a safe environment for patients can prevent this infection. ${ }^{139,177}$ Due to the limitations of obtaining tissue biopsies in these patients and the time-consuming process of diagnosis, it is better to start treatment based on the patient's clinical symptoms, furthermore, developing molecular methods for the diagnosis of mucormycosis can be beneficial and lead to excellent outcomes.

\section{Fusariosis}

Fusarium species causes most common opportunistic fungal infection that is widely distributed in the environment (soil, plant debris, and air) because of the high ability of this fungal family to grow on a broad range of substrates and their competent mechanisms for dispersal. ${ }^{178,179}$ Entry through the airways (inhalation of airborne microconidia) is the most common way of accessing the Fusarium species to the human body, but damaged mucous membranes and skin can also be the site of entry of these microorganisms. ${ }^{180,181}$ Although more than 100 species of Fusarium have been identified so far, most of the human infections are caused by $F$. solani, F. oxysporum, $F$. verticillioides, and $F$. proliferatum. ${ }^{182,183}$ This fungal family can cause local infections in people with healthy immune systems who have skin breakdowns or foreign bodies, but disseminated infections usually occur in immunocompromised patients, and patients with blood malignancies and allogeneic hematopoietic cell transplant recipients are susceptible to fusariosis. ${ }^{183,184}$

Onychomycosis and keratitis are the most common forms of fusariosis in patients, but in immunocompromised patients, Fusarium species can cause infections such as sinusitis, thrombophlebitis, osteomyelitis, pneumonia, and endophthalmitis. ${ }^{185-188}$ In patients with hematologic malignancies, fusariosis like other fungal infections such as aspergillosis is highly invasive due to the immunesystem disorders such as prolonged and deep neutropenia, T-cell immunodeficiency and administration of immunosuppressive drugs. ${ }^{189}$ Along with neutropenia, no cellular inflammatory reactions occur, and this can lead to IFI, since macrophages and neutrophils which invade Fusarium hyphae, inhibit the germination of conidia and the growth of hyphae are absent in neutropenic patients. ${ }^{182,190}$ Noteworthy, Fusarium species are capable of producing mycotoxins, such as trichothecenes, which 
causes tissue damage and suppress humoral and cellular immunity. ${ }^{191}$ Therefore, patients with hematologic malignancies are highly susceptible to fusariosis with a higher chance of spreading the infection due to immune disorders.

All of these indicate the importance of prophylaxis and prevention strategies in these patients. Also, Fusarium species have a very low sensitivity to antifungal drugs, and this causes therapeutic failures in patients with invasive fusariosis, therefore, in these patients, prevention seems to be essential. ${ }^{192}$ Using broad-spectrum azoles, such as voriconazole and posaconazole, can be helpful as prophylaxis; however, few studies have been conducted in this area. On the other hand, some studies have reported that prophylaxis with these drugs does not prevent invasive fusariosis. ${ }^{193,194}$ Also, creating safe environments that have proper filters and air pressure is beneficial for patients with blood malignancies. Furthermore, based on the recent findings, plumbing and water systems are the reservoirs of Fusarium species in hospital environments, and keeping them away from susceptible patients may help hinder fusariosis. ${ }^{181,195}$ Few studies have evaluated the susceptibility of Fusarium species to various antifungal drugs; also, some studies have examined the efficacy of drugs in animal models. Fusarium studies on animal models have many limitations because Fusarium is less virulent in mice and is not pathogenic in guinea pigs that reduces the applicability of animal studies. ${ }^{196-198}$ These microorganisms are not susceptible to echinocandins and itraconazole, and in general, LAMB, voriconazole, and posaconazole have been recommended or applied for the treatment and prophylaxis of fusariosis in adults, although the clinical response to these drugs were merely modest. ${ }^{199,200}$ Harada and his colleagues reported that a patient with AML who also had a pre-engraftment disseminated fusariosis was treated with high doses of LAMB, and the results of another study also showed that a combination of LAMB and voriconazole in an ALL patient with disseminated fusariosis leads to complete recovery of the patient. ${ }^{117,201}$ On the other hand, the results of another study on two acute leukemia patients who developed disseminated fusariosis showed that the $F$. solani isolated from the patients were resistant to amphotericin, and both patients died despite antifungal treatment. $^{202}$ So, antifungal drugs can have different efficacy in patients with different conditions, and this indicates the need for developing antifungal susceptibility tests. Furthermore, antifungal treatment in patients with hematological malignancies with disseminated fusariosis must be aggressive, with high doses of antifungals or combined therapy.

Diagnosis in patients with fusariosis is based on positive cultures of blood and skin lesions. Unlike aspergillosis, blood cultures are positive in this infection because of the production of yeast-like structures (adventitious sporulation) that allow the dissemination and growth of Fusarium species in the blood. ${ }^{203}$ This microorganism grows on most cycloheximide-free media and histopathological examination, observing and finding fungal structures such as Adventitious sporulation, the hyphae, and yeast-like structures together can help confirm the diagnosis. $^{179}$ The $1,3-\beta$-D-glucan test is usually positive in patients with invasive fusariosis, but it is not very helpful because it does not differentiate other IFI, such as candidiasis and aspergillosis. ${ }^{204,205}$ Also, using molecular methods is helpful in the detection of Fusarium species. Herkert et al reported that the use of sequencing translation elongation factor 1-alpha gene showed a good ability to distinguish and differentiate clinical Fusarium species. $^{206}$

Therefore, since Fusarium species cause disseminated infections in patients with hematologic malignancies and these infections are resistant to antifungal treatments, before starting immunosuppressive drugs, patients should be carefully investigated for the presence of infections that involve skin or nail, and more attention should be paid to the cutaneous lesions to reduce the risk of infections by these microorganisms in patients with blood malignancies. Of note, more clinical studies are needed to evaluate the precise function of antifungal agents to inhibit Fusarium species, because proper prophylaxis and treatment of patients with hematologic malignancies may prevent disseminated fusariosis with high mortality in these patients.

\section{Cryptococcosis}

Cryptococcosis is a fungal infection, and most of the time, it demonstrates as meningoencephalitis, pneumonia, and disseminated infection. This fungal infection is usually caused by two different species of Cryptococcus gattii and Cryptococcus neoformans ${ }^{207}$. C. neoformans have been found all around the world, and it is responsible for the majority of the infected cases. C. gattii, on the other hand, has been isolated from a range of plants in British Columbia, Australia, Canada, and the Pacific Northwest of the USA, but recently it has expanded throughout the other parts of the USA. ${ }^{208}$ Cryptococcus species is a regular 
saprophyte in the environment, acquiring nourishment from dying organic material. Exposure to Cryptococcus species occurs through the inhalation of aerosolized basidiospores. Most cases develop hematogenous dissemination with a particular predilection for the CNS, which results in cryptococcal meningitis ( $\sim 90 \%)$ after pulmonary infection. Moreover, occurring lesions in other tissues is another indication for fungus spread. ${ }^{209}$ When the yeasts contact with macrophages in the alveoli of healthy hosts, a type $1 \mathrm{~T}$ helper cell response activates. This pathogen, as a facultative intracellular pathogen, is well adapted to survive intracellularly in the host body. In this respect, Cryptococcus species and macrophages interaction play a significant role in cryptococcal pathogenesis. ${ }^{210}$ Through the non-lytic exocytosis process, C. neoformans can extrude itself from the phagocytic cell. Also, it can alter its phenotype through phenotypic switching and replicative aging, leading to subverted immune responses in the host. ${ }^{211,212}$

The global incidence of $C$. neoformans disease is estimated one million cases leading to 625,000 fatalities each year. ${ }^{213}$ In healthy hosts, the disease is usually asymptomatic, mild or self-limited, whereas patients with deficiencies in T-cell immunity are not capable of forming granulomas. Therefore, in these patients, local pulmonary or disseminated infection to the blood and CNS can occur and result in adverse consequences. ${ }^{214}$ More specifically, the prevalence and history of $C$. neoformans disease are essential since it is highly related to the AIDS epidemic. In the sub-Saharan African region, access to antiretroviral therapy is limited; therefore, the highest rate of cryptococcosis has found in patients in such countries. ${ }^{215}$ Other groups affected by $C$. neoformans infection are those with malignancy, solid organ transplant, cytotoxic chemotherapy, chronic organ failure and lung disease, rheumatologic disorders, splenectomy, idiopathic CD4 lymphocytopenia and even healthy immunocompetent hosts. ${ }^{216}$ Recently, studies have suggested that administration of a high dose of chemotherapeutic regimens that result in depletion of lymphocytes such as rituximab, fludarabine, cyclophosphamide alemtuzumab and extended use of corticosteroids can lead to the elevated risk cryptococcal disease in patients with malignancy. ${ }^{30,217,218}$ Furthermore, Abid et al report a patient with CLL who developed disseminated cryptococcosis (meningitis, probable pneumonia, and fungemia) while receiving ibrutinib therapy. ${ }^{31}$ Another study also reports tow patients with cryptococcal meningoencephalitis and cryptococcal pneumonia who were receiving ibrutinib for CLL. ${ }^{219}$ The results of these studies suggest that a compromised innate and adaptive immunity in CLL patients and further impairments in the humoral and cellmediated immune system as a result of ibrutinib administration increase the chance of cryptococcal infection. Therefore, patients who develop acute illness and simultaneously receive ibrutinib should be examined for cryptococcal antigen.

As mentioned earlier, the association of cryptococcosis with CD4 lymphopenia that determines AIDS is remarkable; therefore, in immunocompromised cancer population with neutropenia, this infection is not typical. ${ }^{30}$ On the other hand, lymphocytic leukemia patients are likely to show hypogammaglobinemia, suppression of helper T-cells, reduced T-cell response to proliferative signals, imbalanced in T-cell subset with an inversion in CD4: CD8 ratio, and a decline in the CD4 T-cell count. Consequently, these patients are mostly associated with higher rates of cryptococcosis. ${ }^{23,220}$ The results of a systematic review study (adult patients published from 1970 to 2014) showed that hematological malignancies are responsible for $82 \%$ of cryptococcal infections in the setting of malignancy. The underlying diseases in such infection were lymphomas, leukemias, and myelomas in $66 \%, 29 \%$, and $4 \%$ of the cases, respectively. There are two factors accounted for this skewed distribution, including the immune dysfunction associated with each malignancy and the particular chemotherapeutic regimen. Patients with lymphoma seem to be at higher risk, and this may be due to a combination of alteration in the immunity-related to cancer and using lymphoma therapeutics that result in T-cell depletion. ${ }^{30}$

Cryptococcosis is typically caused by $C$. neoformans and C. gattii; however, over the past four decades, opportunistic infections associated with non-gattii and nonneoformans species such as C. albidus and C. laurentii have increased significantly. Park et al stated in a study that in disseminated cryptococcosis with skin manifestation in a female with refractory AML after allogeneic hematopoietic stem cell transplantation, the skin biopsy showed fungal hyphae, also, repetitive blood cultures revealed yeast infection that later was detected as C. laurentii using Vitek-II. ${ }^{221}$ Also, another study on pediatric cancer patients with ALL reported that C. magnus and C. chernovii were isolated from cultures inoculated with nasal specimens. ${ }^{222}$ Therefore, severely immunocompromised patients with persistent febrile neutropenia should be considered for non-neoformans, and non-gattii cryptococcosis infections. 
As a result of the atypical presentation, most of the patients receive antibacterial treatments before the accurate diagnosis of cryptococcosis was determined. Recently, most scientists have focused on developing a rapid diagnostic test for cryptococcal disease to enhance its prevention and treatment in infected patients. Conventionally, the diagnosis of such infections relied on lumbar puncture followed by CSF India ink preparation, detection of cryptococcal antigen $(\mathrm{CrAg})$, or culture. ${ }^{223}$ Most recently, researchers have presented a $\mathrm{CrAg}$ test utilizing point-ofcare lateral flow test to identify cryptococcal capsular polysaccharide antigens (particularly glucuronoxylomannan) in blood, CSF, urine, or serum samples. The sensitivity and specificity of this test with $93-100 \%$ and $93-98 \%$, respectively, are comparable to those of latex agglutination, enzyme-linked immunosorbent assay (ELISA), and cultures. ${ }^{224,225}$

The treatment of cryptococcosis relies on the clinical indications and the immunological situation of the patients. Currently, AMB and its lipid formulation, flucytosine, and fluconazole are three drugs known as clinical antifungal assets against cryptococcosis. ${ }^{208}$ In addition to the limited therapeutic options, high rates of attendance and recurrence have been reported due to increase resistance of Cryptococcus species to fluconazole and flucytosine. A recent meta-analysis (29 studies from 1988 to May 2017) reports meaning fluconazole resistance $10.6 \%$ and $24.1 \%$ for the incident isolates and relapse isolates, respectively. Furthermore, $18.7 \%$ of isolates had minimum inhibitory concentration (MIC) above the ecological cut-off value. ${ }^{226}$ Assing et al reported a case of fluconazole-resistant cryptococcal meningitis in a CLL patient that treated with AMB for almost six weeks. Therefore, it seems that fluconazole resistance is a growing concern in Cryptococcus isolates collected from patients with relapses. Thus, susceptibility testing of C. neoformans isolates in all patients with meningeal cryptococcosis is crucial, even in the patient without previous exposure to fluconazole. ${ }^{227}$ Furthermore, the search for new alternatives for the treatment of cryptococcal infections is essential and in previous studies, the use of therapeutic strategies such as IFN- $\gamma^{228}$ mycograb, ${ }^{229}$ a monoclonal antibody directed against the capsular polysaccharide, ${ }^{230}$ sertraline, ${ }^{231}$ and tamoxifen ${ }^{232}$ to control cryptococcosis has been studied.

\section{Trichosporonosis}

As an uncommon, lethal, and opportunistic fungal infection, trichosporonosis affects immunocompromised patients with neutropenia, especially patients with underlying hematologic malignancies. ${ }^{132}$ Trichosporon species that are opportunistic fungal pathogens can lead to a superficial infection known as white piedra, allergic pneumonitis, and invasive infections in humans. ${ }^{233}$ Amongst Trichosporon species, T. asahii and T. cutaneum (formerly: T. beigelii) are the most common ones. After candidiasis, trichosporonosis was considered as the second most frequent infection leading to fungemia in patients with hematological malignancies. ${ }^{234,235}$ Neutropenia is the primary risk factor for trichosporonosis. The other risk factors leading to trichosporonosis are cytotoxic chemotherapy, consumption of systemic corticosteroid, indwelling central catheters, prosthetic valve surgery, organ transplantation, and peritoneal dialysis. ${ }^{132,236}$

A recent systematic review reported that hematological diseases (38.9\% of the cases), mainly acute leukemia, are the most frequent underlying diseases that provide a condition for invasive trichosporonosis (IT). Neutropenia was observed in $85 \%$ of patients with hematological diseases; this supports the fact that neutrophils are, as for aspergillosis and candidiasis, essential for the prevention of IT. ${ }^{234}$ The results of another systematic review on 19 pediatric patients with IT and underlying malignant or nonmalignant hematologic disorder revealed that ALL (47\%) and then AML $(21 \%)$ are the most frequent underlying hematologic disorder. Notably, the mortality rate of $58 \%$ was reported in this study. ${ }^{235}$ Furthermore, another study conducted in Japan on 33 cases of Trichosporon fungemia (TF) in patients with hematologic malignancies reported that most of the patients with TF had acute leukemia (82\%), neutropenia (85\%), and $91 \%$ of them had a history of intensive chemotherapy. Also, in this study, a mortality rate of $76 \%$ was reported in patients with $\mathrm{TF}^{237}$

There was a growing concern in patients who received a systematic antifungal, as therapy or prophylaxis, to develop breakthrough IFI (B-IFI). Trichosporon species has become a critical life-threatening opportunistic pathogen that causes B-IFI during exposure to antifungals. ${ }^{238}$ Also, with higher use of wide-spectrum triazoles as prophylaxis in high-risk patients, infection with multidrug-resistant (MDR) Trichosporon species was reported. ${ }^{239}$ A recent study reported a series of 68 cases who developed breakthrough Trichosporon species infections. The results of this study indicated that $95.5 \%$ of patients had an underlying hematological malignancy. Also, $61.8 \%$ of patients with breakthrough Trichosporon species received echinocandins, 22\% received triazoles, $13.2 \%$ received amphotericin, and 3\% received other combinations of antifungals. The mortality 
Table 2 Other Invasive Fungal Infections Reported in Patients with Hematologic Malignancies

\begin{tabular}{|c|c|c|c|c|c|}
\hline $\begin{array}{l}\text { Fungal } \\
\text { Infection }\end{array}$ & Species & $\begin{array}{l}\text { Underlying } \\
\text { Disease }\end{array}$ & Clinical Manifestation & Outcome & References \\
\hline Coccidioidomycosis & $\begin{array}{l}\text { Coccidioides } \\
\text { species }\end{array}$ & ALL & $\begin{array}{l}\text { Meningitis complicated by central nervous } \\
\text { system vasculitis. }\end{array}$ & $\begin{array}{l}\text { The patient was treated with } \mathrm{AMB} \text {, intravenous } \\
\text { fluconazole, Micafungin and prednisone. }\end{array}$ & 250 \\
\hline \multirow[t]{5}{*}{ Scopulariopsis } & $\begin{array}{l}\text { S. } \\
\text { alboflavescens }\end{array}$ & AML & $\begin{array}{l}\text { Pneumonia with large consolidation on the } \\
\text { left side of the lung hilum. }\end{array}$ & $\begin{array}{l}\text { AMB and voriconazole combination therapy was } \\
\text { not successful and the patient died. }\end{array}$ & 251 \\
\hline & S. brevicaulis & AML & $\begin{array}{l}\text { Bronchial invasion that leads to mediastinal } \\
\text { emphysema, bronchial bleeding, and } \\
\text { bronchial obstruction before finally } \\
\text { spreading to the entire lung. }\end{array}$ & $\begin{array}{l}\text { The patient died because it was estimated that } \\
\text { the patient had respiratory aspergillosis infection, } \\
\text { and the optimal treatment was delayed. }\end{array}$ & 252 \\
\hline & S. brevicaulis & AML & $\begin{array}{l}\text { The patient with necrotic ulcers on his } \\
\text { hard palate and his left tonsil. }\end{array}$ & $\begin{array}{l}\text { Sinonasal infection was successfully treated with } \\
\text { a combination of extensive surgical debridement } \\
\text { and } \mathrm{AMB} \text {. }\end{array}$ & 253 \\
\hline & S. brevicaulis & AML & $\begin{array}{l}\text { The patient with persistent fever that did } \\
\text { not respond to wide spectrum antibiotics } \\
\text { and } A M B \text {. }\end{array}$ & $\begin{array}{l}\text { The fever subsided with itraconazole, and there } \\
\text { was no recurrence of fungal infection with } \\
\text { prolonged maintenance of oral itraconazole. }\end{array}$ & 254 \\
\hline & S. brevicaulis & AML & $\begin{array}{l}\text { Onychomycosis with local cutaneous } \\
\text { invasion. }\end{array}$ & $\begin{array}{l}\text { Unsuccessfully treated with high-dose micafungin, } \\
\text { and the patient died from a cerebral hemorrhage } \\
\text { in the context of chronic thrombocytopenia. }\end{array}$ & 255 \\
\hline \multirow[t]{5}{*}{ Geoterichosis } & G. capitatum & ALL & The patient with fever and blood infection. & $\begin{array}{l}\text { The patient died and fungal infection disseminated } \\
\text { although caspofungin was used as prophylaxis. }\end{array}$ & 256 \\
\hline & G. capitatum & $\begin{array}{l}\text { Fanconi } \\
\text { aplastic } \\
\text { anemia }\end{array}$ & $\begin{array}{l}\text { Neutropenic fever, multiple nodules were } \\
\text { detected in liver and septic arthritis. }\end{array}$ & $\begin{array}{l}\text { The patient treated with } \mathrm{AMB} \text { and voriconazole } \\
\text { but died due to sepsis and multiple organ failure. }\end{array}$ & 257 \\
\hline & G. capitatum & $\begin{array}{l}\text { AML with } \\
\text { multilineage } \\
\text { dysplasia }\end{array}$ & $\begin{array}{l}\text { Blood infection and multiple nodular } \\
\text { lesions in lung fields. }\end{array}$ & $\begin{array}{l}\text { The patient treated with a combination of } \mathrm{AMB} \text {, } \\
\text { itraconazole, and voriconazole. }\end{array}$ & 258 \\
\hline & G. capitatum & $\begin{array}{l}\text { Plasma cell } \\
\text { leukemia }\end{array}$ & Pneumonia & $\begin{array}{l}\text { The patient treated successfully with an antifungal } \\
\text { combination of voriconazole, caspofungin, and } \\
\text { supportive therapy. }\end{array}$ & 259 \\
\hline & G. capitatum & ALL & The infection involved lung, liver and skin & $\begin{array}{l}\text { Caspofungin, } \mathrm{AMB} \text {, and combination therapy with } \\
\text { voriconazole improved patient condition, but the } \\
\text { patient died due to heart and lung failure. }\end{array}$ & 260 \\
\hline $\begin{array}{l}\text { Ochroconis } \\
\text { gallopavum }\end{array}$ & $\begin{array}{l}\text { Ochroconis } \\
\text { gallopavum }\end{array}$ & B-CLL & Disseminated Infection & $\begin{array}{l}\mathrm{AMB} \text { and itraconazole were used for treatment, } \\
\text { but the patient died due to brain abscesses. }\end{array}$ & 261 \\
\hline \multirow[t]{4}{*}{ Scedosporium } & S. prolificans & AML & Disseminated Infection & $\begin{array}{l}\text { Combination of voriconazole and terbinafine in } \\
\text { conjunction with central venous line removal and } \\
\text { intravitreal voriconazole, contributed to the } \\
\text { recovery of the patient. }\end{array}$ & 262 \\
\hline & S. prolificans & ALL & Pneumonia & $\begin{array}{l}\text { Successfully treated with liposomal AMB and who } \\
\text { underwent autologous peripheral blood stem } \\
\text { cells transplantation. }\end{array}$ & 263 \\
\hline & S. prolificans & AML & Sepsis & $\begin{array}{l}\text { Died AML and Fatal S. prolificans sepsis after } \\
\text { Eculizumab treatment for paroxysmal nocturnal } \\
\text { hemoglobinuria. }\end{array}$ & 264 \\
\hline & S. prolificans & AML & Infective endocarditis & $\begin{array}{l}\text { Died } \\
\text { Multi-organ failure despite the combined use of } \\
\text { voriconazole and terbinafine. }\end{array}$ & 265 \\
\hline
\end{tabular}

Abbreviations: AMB, amphotericin B; ALL, acute lymphocytic leukemia; AML, acute myeloid leukemia; CLL, chronic lymphocytic leukemia. 
rate reported in this study was $68.7 \%$, and both neutropenia and the presence of venous catheters were considered as crucial factors for developing infection. ${ }^{131}$ Furthermore, Suzuki et al reported that TF occurred as a B-IFI during antifungal therapy in 30 patients (91\%), 18 of whom were receiving micafungin. Therefore, they suggested that along with using antifungals without anti-Trichosporon activity, further care is needed to prevent the development of breakthrough trichosporonosis. ${ }^{237}$ Another study also reported an elderly, a 73 years old man, with AML and T. asahii systemic infection who received itraconazole as prophylaxis during severe neutropenia. Notably, this case was successfully treated with voriconazole following LAMB. ${ }^{240}$ Thus, breakthrough trichosporonosis is a severe and life-threatening infection that occurs in immunocompromised patients, commonly under antifungal selective pressure. Generally, underlying diseases accompanied by neutropenia are mostly accompanied by deleterious outcomes. ${ }^{131}$

Recent studies have shown that the tendency for trichosporonosis to evade detection on blood culture and to resemble other better-known pathogens such as Candida on histology present additional diagnostic challenges. ${ }^{241}$ It has been suggested that compared with Candida, Trichosporon has thinner hyphae and pseudohyphae, and stain slightly on Gomori methenamine silver (GMS) in comparison to other fungi. Nonetheless, histopathological detection of Trichosporon without immunohistochemistry, ELISA, and/or PCR confirmation is challenging. ${ }^{242,243}$ Galligan et al reported a disseminated T. asahii case in a relapsed ALL patient who received systematic antifungal therapy and indicated multiple cutaneous nodules suggestive a fungal infection. Although histological characteristics resembled neutrophilic eccrine hidradenitis but staining with periodic acid-Schiff stain (PAS) and GMS confirmed the clinical diagnosis. ${ }^{241}$ Thus, trichosporonosis must be distinguished from candidiasis and other diseases, which share similar clinical and morphologic features in the disseminated form and their differences in treatment susceptibility.

Optimal therapy for disseminated trichosporonosis is not established. Recently, various organizations, including the European Society for Clinical Microbiology and Infectious Diseases and the European Confederation of Medical Mycology, suggested voriconazole as an optimal and fluconazole as a suboptimal therapeutic line for the treatment of trichosporonosis. ${ }^{244}$ MDR Trichosporon has been reported with AMB, echinocandins, flucytosine, fluconazole, and itraconazole. $^{131,233,236}$ Another study reported that during multi-agent chemotherapy, two patients with hematologic malignancy developed endophthalmitis as a result of T. beigelii infection. Trichosporonous endophthalmitis in these patients was resistant to fluconazole and 5-fluorocytosine, and in both cases, systematic treatment with AMB efficiently resolved this infection, which was resistant to antifungal therapeutics. Therefore, the result of this study suggests that the treatment of endophthalmitis as a result of trichosporonosis is challenging. ${ }^{245}$ In this respect, an urgent need for a novel antifungal drug appears. In vitro investigations indicates that new antifungals such as posaconazole and voriconazole are efficient against Trichosporon; also, other studies have reported good clinical outcomes. ${ }^{246-248}$ On the other hand, recent researches reported that compared to antifungal treatments, improving trichosporonosis mostly depends on neutrophil recovery. This suggests that prophylaxis with antifungal drugs, even azoles, may not deliver complete prevention against trichosporonosis in patients with acute neutropenia. ${ }^{240,249}$

Therefore, trichosporonosis should be considered as a crucial factor in the evaluation of neutropenic immunocompromised patients, especially those with underlying hematologic malignancies, because it carries significant mortality and delayed diagnosis and therapy results in death. Moreover, this infection in severely neutropenic patients should be considered in the differential diagnosis of refractory fever regardless of using echinocandins and azoles as prophylaxis medication. Finally, Table 2 summarizes other IFI in patients with hematologic malignancies. Although these infections are less common, they lead to therapeutic failures and high mortality rates in patients with hematologic malignancies.

\section{Conclusion and Perspective}

The increasing prevalence of IFI in patients with hematologic malignancies has raised many concerns. These patients are prone to fungal infections due to disorders of the innate immune system. The incidence of drug resistance in different fungal species has increased the mortality rate of disseminated infection in patients with hematologic malignancies. Prophylaxis and prevention of patients' contact with environmental sources of microorganisms can be effective in preventing infection. Traditional diagnostic methods are limited due to the lack of access to suitable biopsy specimens in patients with hematologic malignancies, and rapid molecular methods with higher rates of accuracy can be used more widely. Finally, because of the infections in recent years, 
further studies on the use of new drugs, immunotherapies, combination therapies and drug resistance in fungal infections is recommended to help prevent the high mortality rate of these infections in patients with hematologic malignancies.

\section{Acknowledgment}

We greatly appreciate the input from Melika Khanzadeh Tehrani (from Department of Pathobiology, School of Public Health, Tehran University of Medical Sciences, Tehran, Iran) for her collaboration with us in figures design.

\section{Disclosure}

The authors report no conflicts of interest in this work.

\section{References}

1. Hoffbrand AV, Steensma DP. Hoffbrand's Essential Haematology. John Wiley \& Sons; 2019.

2. Rodak BF, Keohane EM, Fritsma GA. Hematology-E-Book: Clinical Principles and Applications. Elsevier Health Sciences; 2013.

3. Papon N, Bougnoux M-E, d'Enfert C. Tracing the origin of invasive fungal infections. Trends Microbiol. 2020.

4. Hovi L, Saarinen-Pihkala U, Vettenranta K, Saxen H. Invasive fungal infections in pediatric bone marrow transplant recipients: single center experience of 10 years. Bone Marrow Transplant. 2000;26(9):999-1004. doi:10.1038/sj.bmt.1702654

5. Nosari AM, Pioltelli ML, Riva M, et al. Invasive fungal infections in lymphoproliferative disorders: a monocentric retrospective experience. Leuk Lymphoma. 2014;55(8):1844-1848. doi:10.3109/10428194.2013.853299

6. Varughese T, Taur Y, Cohen N, et al. Serious infections in patients receiving ibrutinib for treatment of lymphoid cancer. Clin Infect Dis. 2018;67(5):687-692. doi:10.1093/cid/ciy175

7. Lawrence MB, Springer T. Neutrophils roll on E-selectin. J Immunol. 1993;151(11):6338-6346.

8. Milošević N, Rütter M, Ventura Y, Kezerle Y, Feinshtein V, David A. Attenuation of neutrophil-mediated liver injury in mice by drug-free E-selectin binding polymer. $J$ Controlled Release. 2020;319:475-486.

9. Sasaki T, Irie-Sasaki J, Jones RG, et al. Function of PI3K $\gamma$ in thymocyte development, T cell activation, and neutrophil migration. Science. 2000;287(5455):1040-1046.

10. Zhang P, Yue K, Liu X, et al. Endothelial Notch activation promotes neutrophil transmigration via downregulating endomucin to aggravate hepatic ischemia/reperfusion injury. Sci China Life Sci. 2020;1-13.

11. Stark A-K, Sriskantharajah S, Hessel EM, Okkenhaug K. PI3K inhibitors in inflammation, autoimmunity and cancer. Curr Opin Pharmacol. 2015;23:82-91. doi:10.1016/j.coph.2015.05.017

12. Harding JJ, Bauer TM, Tan DS, et al. Characterization and Phase I study of CLR457, an orally bioavailable pan-class I PI3-kinase inhibitor. Invest New Drugs. 2019;37(2):271-281. doi:10.1007/ s10637-018-0627-4

13. Greenwell I, Flowers C, Blum K, Cohen J. Clinical use of PI3K inhibitors in B-cell lymphoid malignancies: today and tomorrow. Expert Rev Anticancer Ther. 2017;17(3):271-279. doi:10.1080/ 14737140.2017.1285702
14. Cheah CY, Fowler NH. Idelalisib in the management of lymphoma. Blood. 2016;128(3):331-336. doi:10.1182/blood2016-02-702761

15. Lampson BL, Kim HT, Davids MS, et al. Efficacy results of a Phase 2 trial of first-line idelalisib plus ofatumumab in chronic lymphocytic leukemia. Blood Adv. 2019;3(7):1167-1174. doi:10.1182/bloodadvances.2018030221

16. Moradabadi A, Farsinejad A, Khansarinejad B, Fatemi A. Development of a high resolution melting analysis assay for rapid identification of JAK2 V617F missense mutation and its validation. Exp Hematol Oncol. 2019;8(1):10. doi:10.1186/ s40164-019-0134-0

17. Vafadari R, Weimar W, Baan CC. Phosphospecific flow cytometry for pharmacodynamic drug monitoring: analysis of the JAK-STAT signaling pathway. Clinica Chimica Acta. 2012;413 (17-18):1398-1405. doi:10.1016/j.cca.2011.12.023

18. Taherahmadi H, Moradabadi AR, Arjomand Shabestari A, Nazari J, Kahbazi MK. Antibiotic induced hemolytic anemia and thrombocytopenia among pediatric patients admitted to intensive care unit. Iran J Ped Hematol Oncol. 2019;9(1):9-16.

19. Branzk N, Lubojemska A, Hardison SE, et al. Neutrophils sense microbe size and selectively release neutrophil extracellular traps in response to large pathogens. Nat Immunol. 2014;15 (11):1017-1025. doi:10.1038/ni.2987

20. Lionakis MS, Iliev ID, Hohl TM. Immunity against fungi. JCI Insight. 2017;2(11):11. doi:10.1172/jci.insight.93156

21. Lionakis MS, Netea MG, Holland SM. Mendelian genetics of human susceptibility to fungal infection. Cold Spring Harb Perspect Med. 2014;4(6):a019638. doi:10.1101/cshperspect. a019638

22. King J, Henriet SS, Warris A. Aspergillosis in chronic granulomatous disease. J Fungi. 2016;2(2):15. doi:10.3390/jof2020015

23. Suleman A, Padmore R, Faught C, Cowan J. Disseminated cryptococcal infection in a patient with treatment-naïve chronic lymphocytic leukemia (CLL). IDCases. 2019;17:e0566. doi:10.1016/j.idcr.2019.e00566

24. Hohl TM. Overview of vertebrate animal models of fungal infection. J Immunol Methods. 2014;410:100-112. doi:10.1016/j. jim.2014.03.022

25. Mariette C, Tavernier E, Hocquet D, et al. Epidemiology of invasive fungal infections during induction therapy in adults with acute lymphoblastic leukemia: a GRAALL-2005 study. Leuk Lymphoma. 2017;58(3):586-593. doi:10.1080/10428194.20 16.1204652

26. Crawford J, Dale DC, Lyman GH. Chemotherapy-induced neutropenia: risks, consequences, and new directions for its management. Cancer. 2004;100(2):228-237. doi:10.1002/cncr.11882

27. Bakhshi S, Padmanjali K, Arya L. Infections in childhood acute lymphoblastic leukemia: an analysis of 222 febrile neutropenic episodes. Pediatr Hematol Oncol. 2008;25(5):385-392. doi:10.1080/08880010802106564

28. Gerson SL, Talbot GH, Hurwitz S, STROM BL, Lusk EJ, Cassileth PA. Prolonged granulocytopenia: the major risk factor for invasive pulmonary aspergillosis in patients with acute leukemia. Ann Intern Med. 1984;100(3):345-351. doi:10.7326/ 0003-4819-100-3-345

29. Newburger PE, Dale DC. Evaluation and management of patients with isolated neutropenia. Semin Hematol. 2013;50(3):198-206. doi:10.1053/j.seminhematol.2013.06.010

30. Schmalzle SA, Buchwald UK, Gilliam BL, Riedel DJ. Cryptococcus neoformans infection in malignancy. Mycoses. 2016;59(9):542-552. doi:10.1111/myc. 12496

31. Abid MB, Stromich J, Gundacker ND. Is ibrutinib associated with disseminated cryptococcosis with CNS involvement? Cancer Biol Ther. 2019;20(2):138-140. doi:10.1080/15384047.2018.1508622 
32. Kontoyiannis DP, Georgiadou SP, Wierda WG, et al. Impaired bactericidal but not fungicidal activity of polymorphonuclear neutrophils in patients with chronic lymphocytic leukemia. Leuk Lymphoma. 2013;54(8):1730-1733. doi:10.3109/10428194.2012.750723

33. Beyer M, Kochanek M, Darabi K, et al. Reduced frequencies and suppressive function of $\mathrm{CD} 4+\mathrm{CD} 25$ hi regulatory $\mathrm{T}$ cells in patients with chronic lymphocytic leukemia after therapy with fludarabine. Blood. 2005;106(6):2018-2025. doi:10.1182/blood-2005-02-0642

34. Mosayebi M, Eslamirad Z, Hajihossein R, Ghorbanzadeh B, Shahverdi M, Didehdar M. Evaluating of fungal contamination in hospital wet cooling systems in Markazi province, Central Iran. J Mycol Med. 2017;27 (3):334-338. doi:10.1016/j.mycmed.2017.04.003

35. Frange $P$, Bougnoux M-E, Lanternier $F$, et al. An update on pediatric invasive aspergillosis. Med Mal Infect. 2015;45 (6):189-198. doi:10.1016/j.medmal.2015.04.006

36. Burgos A, Zaoutis TE, Dvorak CC, et al. Pediatric invasive aspergillosis: a multicenter retrospective analysis of 139 contemporary cases Pediatrics. 2008;121(5):e1286-e1294. doi:10.1542/peds.2007-2117

37. Thomas KE, Owens CM, Veys PA, Novelli V, Costoli V. The radiological spectrum of invasive aspergillosis in children: a 10-year review. Pediatr Radiol. 2003;33(7):453-460. doi:10.1007/s00247-003-0919-4

38. Assendorp EL, Gresnigt MS, Sprenkeler EGG, et al. Adjunctive interferon-gamma immunotherapy in a pediatric case of Aspergillus terreus infection. Eur J Clin Microbiol Infect Dis. 2018;37(10):1915-1922. doi:10.1007/s10096-018-3325-4

39. Bassetti M, Bouza E. Invasive mould infections in the ICU setting: complexities and solutions. $J$ Antimicrob Chemother. 2017;72(supp1_1):i39-i47. doi:10.1093/jac/dkx032

40. Taccone FS, Van den Abeele A-M, Bulpa P, et al. Epidemiology of invasive aspergillosis in critically ill patients: clinical presentation, underlying conditions, and outcomes. Crit Care. 2015;19 (1):7. doi:10.1186/s13054-014-0722-7

41. Khasawneh F, Mohamad T, Moughrabieh MK, Lai Z, Ager J, Soubani AO. Isolation of Aspergillus in critically ill patients: a potential marker of poor outcome. J Crit Care. 2006;21 (4):322-327. doi:10.1016/j.jcrc.2006.03.006

42. Cornillet A, Camus C, Nimubona S, et al. Comparison of epidemiological, clinical, and biological features of invasive aspergillosis in neutropenic and nonneutropenic patients: a 6-year survey. Clin Infect Dis. 2006;43(5):577-584. doi:10.1086/505870

43. Vandewoude K, Blot S, Benoit D, Depuydt P, Vogelaers D, Colardyn F. Invasive aspergillosis in critically ill patients: analysis of risk factors for acquisition and mortality. Acta Clin Belg. 2004;59(5):251-257. doi:10.1179/acb.2004.037

44. Dimopoulos G, Frantzeskaki F, Poulakou G, Armaganidis A. Invasive aspergillosis in the intensive care unit. Ann $N$ Y Acad Sci. 2012;1272(1):31-39. doi:10.1111/j.1749-6632.2012.06805.x

45. Borys M, Piwowarczyk P, Sysiak J, Czuczwar M, Prystupa A. Early diagnosis and treatment of invasive aspergillosis as a main determinant of outcome - review of literature according to the presented case report. Ann Agric Environ Med. 2017;24 (1):100-103. doi:10.5604/12321966.1233966

46. Papachristou S, Iosifidis E, Roilides E. Invasive Aspergillosis in Pediatric Leukemia Patients: prevention and Treatment. J Fungi. 2019;5(1):14. doi:10.3390/jof5010014

47. Crassard N, Hadden H, Pondarré C, et al. Invasive aspergillosis and allogeneic hematopoietic stem cell transplantation in children: a 15-year experience. Transplant Infect Dis. 2008;10 (3):177-183. doi:10.1111/j.1399-3062.2008.00304.x

48. Groll AH, Castagnola E, Cesaro S, et al. Fourth European Conference on Infections in Leukaemia (ECIL-4): guidelines for diagnosis, prevention, and treatment of invasive fungal diseases in paediatric patients with cancer or allogeneic haemopoietic stem-cell transplantation. Lancet Oncol. 2014;15(8):e327-e340. doi:10.1016/S1470-2045(14)70017-8
49. Rosillo C, Avila AM, Huang YT, et al. Sequential systematic anti-mold prophylaxis with micafungin and voriconazole results in very low incidence of invasive mold infections in patients undergoing allogeneic hematopoietic stem cell transplantation. Transpl Infect Dis. 2018;20(4): e12897. doi:10.1111/tid.12897

50. Huang K, Qiu KY, Deng LL, et al. [A clinical analysis of micafungin treatment of pulmonary invasive fungal infection in pediatric patients with acute leukemia or post hematopoietic stem cells transplantation]. Zhonghua Er Ke Za Zhi. 2017;55(11):844-847. Chinese. doi:10.3760/cma.j.issn.0578-1310.2017.11.011

51. Vardakas KZ, Michalopoulos A, Falagas ME. Fluconazole versus itraconazole for antifungal prophylaxis in neutropenic patients with haematological malignancies: a meta-analysis of randomised-controlled trials. $\mathrm{Br} J$ Haematol. 2005;131(1):22-28. doi:10.1111/j.1365-2141.2005.05727.x

52. Fontana L, Perlin DS, Zhao Y, et al. Isavuconazole prophylaxis in patients with hematologic malignancies and hematopoietic cell transplant recipients. Clin Infect Dis. 2020;70(5):723-730. doi:10.1093/cid/ciz282

53. Tomblyn M, Chiller T, Einsele H, et al. Guidelines for preventing infectious complications among hematopoietic cell transplant recipients: a global perspective. Bone Marrow Transplant. 2009;44(8):453-455. doi:10.1038/bmt.2009.254

54. Patterson TF, Thompson GR III, Denning DW, et al. Practice guidelines for the diagnosis and management of aspergillosis: 2016 update by the Infectious Diseases Society of America. Clin Infect Dis. 2016;63(4):e1-e60. doi:10.1093/cid/ciw326

55. Le Clech L, Uguen M, Quinio D, et al. Evaluation of posaconazole antifungal prophylaxis in reducing the incidence of invasive aspergillosis in patients with acute myeloid leukemia. Curr Res Transl Med. 2020;68(1):23-28. doi:10.1016/ j.retram.2019.11.002

56. Kimura S. Invasive Aspergillosis in hematological patients. Med Mycol J. 2016;57(2):J77-88. doi:10.3314/mmj.57.J77

57. Metan G, Keklik M, Dinc G, et al. Performance of Galactomannan Antigen, Beta-d-Glucan, and Aspergillus-lateral-flow device for the diagnosis of invasive aspergillosis. Indian J Hematol Blood Transfus. 2017;33(1):87-92. doi:10.1007/s12288-016-0653-3

58. Aguado JM, Vazquez L, Fernandez-Ruiz M, et al. Serum galactomannan versus a combination of galactomannan and polymerase chain reaction-based Aspergillus DNA detection for early therapy of invasive aspergillosis in high-risk hematological patients: a randomized controlled trial. Clin Infect Dis. 2015;60 (3):405-414. doi:10.1093/cid/ciu833

59. Patterson TF, Donnelly JP. New concepts in diagnostics for invasive mycoses: non-culture-based methodologies. J Fungi (Basel). 2019;5:1.

60. Patterson TF, Donnelly JP. New concepts in diagnostics for invasive mycoses: non-culture-based methodologies. J Fungi. 2019;5 (1):9. doi:10.3390/jof5010009

61. Eigl S, Prattes J, Lackner M, et al. Multicenter evaluation of a lateral-flow device test for diagnosing invasive pulmonary aspergillosis in ICU patients. Crit Care. 2015;19(1):178. doi:10.1186/ s13054-015-0905-x

62. Prattes J, Flick H, Prüller F, et al. Novel tests for diagnosis of invasive aspergillosis in patients with underlying respiratory diseases. Am J Respir Crit Care Med. 2014;190(8):922-929. doi:10.1164/rccm.201407-1275OC

63. Thornton C, Johnson G, Agrawal S. Detection of invasive pulmonary aspergillosis in haematological malignancy patients by using lateral-flow technology. JoVE (Journal of Visualized Experiments). 2012;(61):e3721.

64. Pan Z, Fu M, Zhang J, Zhou H, Fu Y, Zhou J. Diagnostic accuracy of a novel lateral-flow device in invasive aspergillosis: a meta-analysis. J Med Microbiol. 2015;64(7):702-707. doi:10. 1099/jmm.0.000092 
65. White PL, Parr C, Thornton C, Barnes RA. Evaluation of real-time PCR, galactomannan enzyme-linked immunosorbent assay (ELISA), and a novel lateral-flow device for diagnosis of invasive aspergillosis. J Clin Microbiol. 2013;51(5):1510-1516. doi:10.1128/JCM.03189-12

66. Heldt S, Hoenigl M. Lateral flow assays for the diagnosis of invasive aspergillosis: current status. Curr Fungal Infect Rep. 2017;11(2):45-51. doi:10.1007/s12281-017-0275-8

67. Iosifidis E, Papachristou S, Roilides E. Advances in the treatment of mycoses in pediatric patients. J Fungi. 2018;4(4):115. doi:10.3390/jof4040115

68. Miceli MH, Kauffman CA. Isavuconazole: a new broad-spectrum triazole antifungal agent. Clin Infect Dis. 2015;61 (10):1558-1565. doi:10.1093/cid/civ571

69. Van Der Linden JW, Warris A, Verweij PE. Aspergillus species intrinsically resistant to antifungal agents. Med Mycol. 2011;49 (Supplement_1):S82-S89. doi:10.3109/13693786.2010.499916

70. Verweij PE, Ananda-Rajah M, Andes D, et al. International expert opinion on the management of infection caused by azole-resistant Aspergillus fumigatus. Drug Resist Updates. 2015;21:30-40. doi:10.1016/j.drup.2015.08.001

71. Ullmann AJ, Aguado JM, Arikan-Akdagli S, et al. Diagnosis and management of Aspergillus diseases: executive summary of the 2017 ESCMID-ECMM-ERS guideline. Clin Microbiol Infect. 2018;24:e1-e38. doi:10.1016/j.cmi.2018.01.002

72. Postina P, Skladny J, Boch T, et al. Comparison of two molecular assays for detection and characterization of aspergillus fumigatus triazole resistance and Cyp51A mutations in clinical isolates and primary clinical samples of immunocompromised patients. Front Microbiol. 2018;9:555. doi:10.3389/fmicb.2018.00555

73. Bellanger A-P, Berceanu A, Scherer E, et al. Invasive fungal disease, isavuconazole treatment failure, and death in acute myeloid leukemia patients. Emerg Infect Dis. 2019;25(9):1778. doi:10.3201/eid2509.190598

74. Mohammadi F, Hashemi SJ, Zoll J, et al. Quantitative analysis of single-nucleotide polymorphism for rapid detection of TR34/ L98H- and TR46/Y121F/T289A-positive aspergillus fumigatus isolates obtained from patients in Iran from 2010 to 2014. Antimicrob Agents Chemother. 2016;60(1):387-392. doi:10.11 28/AAC.02326-15

75. Dong M, Li X, Liu J, et al. Successful surgical management of invasive pulmonary fungal infection in patients with leukemia. Infect Drug Resist. 2019;12:1675. doi:10.2147/ IDR.S189576

76. Fischer J, Simon T, Hamprecht A, et al. Surgical implications for diagnosis and treatment of intestinal aspergillosis in pediatric patients with ALL. Eur J Pediatr Surg. 2018;28(6):477-483. doi:10.1055/s-0037-1607194

77. Estcourt LJ, Stanworth SJ, Doree C, et al. Granulocyte transfusions for preventing infections in people with neutropenia or neutrophil dysfunction. Cochrane Database Syst Rev. 2015;6.

78. Perruccio K, Tosti A, Burchielli E, et al. Transferring functional immune responses to pathogens after haploidentical hematopoietic transplantation. Blood. 2005;106(13):4397-4406.

79. Wisplinghoff H, Bischoff T, Tallent SM, Seifert H, Wenzel RP, Edmond MB. Nosocomial bloodstream infections in US hospitals: analysis of 24,179 cases from a prospective nationwide surveillance study. Clin Infect Dis. 2004;39(3):309-317.

80. Boktour MR, Kontoyiannis DP, Hanna HA, et al. Multiple-species candidemia in patients with cancer. Cancer. 2004;101 (8):1860-1865.

81. Playford EG, Lipman J, Jones M, et al. Problematic dichotomization of risk for Intensive Care Unit (ICU)-Acquired Invasive Candidiasis: results using a risk-predictive model to categorize 3 levels of risk from a multicenter prospective cohort of Australian ICU patients. Clin Infect Dis. 2016;63(11):1463-1469.
82. Bassetti M, Righi E, Ansaldi F, et al. A multicenter multinational study of abdominal candidiasis: epidemiology, outcomes and predictors of mortality. Intensive Care Med. 2015;41 (9):1601-1610.

83. Kullberg BJ, Arendrup MC. Invasive candidiasis. N Engl J Med. 2015;373(15):1445-1456.

84. Colombo A, de Almeida Júnior J, Slavin MA, Chen SC, Sorrell TC. Candida and invasive mould diseases in non-neutropenic critically ill patients and patients with haematological cancer. Lancet Infect Dis. 2017;17(11):e344-e356.

85. Cornely OA, Gachot B, Akan H, et al. Epidemiology and outcome of fungemia in a cancer Cohort of the Infectious Diseases Group (IDG) of the European Organization for Research and Treatment of Cancer (EORTC 65031). Clin Infect Dis. 2015;61 (3):324-331.

86. Lortholary O, Renaudat C, Sitbon K, et al. The risk and clinical outcome of candidemia depending on underlying malignancy. Intensive Care Med. 2017;43(5):652-662.

87. Yousefi M, Yadegarynia D, Lotfali E, Arab-Mazar Z, Ghajari A, Fatemi A. Candidemia in febrile neutropenic patients; a brief report. Emergency. 2018;6:1.

88. Duque JSR, To KK, Chiang AK, et al. Candida Tropicalis renal microabscesses in a child with leukemia confirmed using nucleic acid amplification and recovery after prolonged antifungal and corticosteroid treatment. Int J Infect Dis. 2019;81:110-113.

89. Alves J, Palma P, Azevedo D, Rello J. Candidemia in the patient with malignancy. Hosp Pract (1995). 2018;46(5):246-252.

90. Gong X, Yang M, Lin D, et al. Candidemia in patients with acute leukemia: analysis of 7 years' experience at a single center in China. Mediterr J Hematol Infect Dis. 2020;12:1.

91. Tang JL, Kung HC, Lei WC, et al. High incidences of invasive fungal infections in acute myeloid leukemia patients receiving induction chemotherapy without systemic antifungal prophylaxis: a prospective observational study in Taiwan. PLoS One. 2015;10 (6):e0128410.

92. Hamzehee S, Kalantar-Neyestanaki D, Mohammadi MA, Nasibi S, Mousavi SAA. Identification of Candida spp. isolated from oral mucosa in patients with leukemias and lymphomas in Iran. Iran J Microbiol. 2019;11(2):114.

93. Kumar J, Singh A, Seth R, Xess I, Jana M, Kabra SK. Prevalence and predictors of invasive fungal infections in children with persistent febrile neutropenia treated for acute leukemia-a prospective study. Ind J Pediatrics. 2018;85(12):1090-1095.

94. Rausch CR, Kontoyiannis DP. Prolonged voriconazole treatment in a patient with chronic lymphocytic leukemia resulting in a litany of chronic overlapping toxicities. J Oncol Pharm Pract. 2019;25(3):747-753.

95. Zonios DI, Banacloche JG, Childs R, Bennett JE. Hallucinations during voriconazole therapy. Clin Infect Dis. 2008;47(1):e7-e10.

96. Cesaro S, Tridello G, Blijlevens $\mathrm{N}$, et al. Incidence, risk factors, and long-term outcome of acute leukemia patients with early candidemia after allogeneic stem cell transplantation: a study by the acute leukemia and infectious diseases working parties of european society for blood and marrow transplantation. Clin Infect Dis. 2018;67(4):564-572.

97. Fan X, Xiao M, Zhang D, et al. Molecular mechanisms of azole resistance in Candida tropicalis isolates causing invasive candidiasis in China. Clin Microbiol Infect. 2019;25(7):885-891.

98. You L, Qian W, Yang Q, et al. ERG11 gene mutations and MDR1 upregulation confer pan-azole resistance in candida tropicalis causing disseminated candidiasis in an acute lymphoblastic leukemia patient on posaconazole prophylaxis. Antimicrob Agents Chemother. 2017;61:7.

99. Mohammadi R, Foroughifar E. Candida infections among neutropenic patients. Caspian J Intern Med. 2016;7(2):71-77. 
100. Mohammadi R, Abdi S. Molecular identification of Candida species isolated from gastro-oesophageal candidiasis in Tehran, Iran. Gastroenterol Hepatol Bed Bench. 2015;8(4):288-293.

101. Ashrafi M, Nabili M, Shokohi T, Janbabaie G, Hedayati MT, AliMoghaddam K. A real time PCR assay on blood for diagnosis of invasive candidiasis in immunocompromised patient. Curr Med Mycol. 2015;1(1):35-41. doi:10.18869/acadpub.cmm.1.1.35

102. Zacharioudakis IM, Zervou FN, Mylonakis E. T2 magnetic resonance assay: overview of available data and clinical implications. J Fungi. 2018;4(2):45. doi:10.3390/jof4020045

103. Mylonakis E, Clancy CJ, Ostrosky-Zeichner L, et al. T2 magnetic resonance assay for the rapid diagnosis of candidemia in whole blood: a clinical trial. Clin Infect Dis. 2015;60(6):892-899.

104. Clancy CJ, Pappas PG, Vazquez J, et al. Detecting infections rapidly and easily for candidemia trial, Part 2 (DIRECT2): a prospective, multicenter study of the T2Candida panel. Clin Infect Dis. 2018;66(11):1678-1686. doi:10.1093/cid/cix1095

105. Muñoz P, Vena A, Machado M, et al. T2MR contributes to the very early diagnosis of complicated candidaemia. A prospective study. J Antimicrob Chemother. 2018;73(suppl_4):iv13-iv19. doi:10.1093/jac/dky048

106. Mylonakis E, Clancy CJ, Ostrosky-Zeichner L, et al. T2 magnetic resonance assay for the rapid diagnosis of candidemia in whole blood: a clinical trial. Clin Infect Dis. 2015;60(6):892-899.

107. Li TY, Liu BH, Chen YC. Characterization of Aspergillus spores by matrix-assisted laser desorption/ionization time-of-flight mass spectrometry. Rapid Commun Mass Spectrometry. 2000;14(24):2393-2400.

108. Mellmann A, Cloud J, Maier T, et al. Evaluation of matrix-assisted laser desorption ionization-time-of-flight mass spectrometry in comparison to $16 \mathrm{~S}$ rRNA gene sequencing for species identification of nonfermenting bacteria. J Clin Microbiol. 2008;46(6):1946-1954. doi:10.1128/JCM.00157-08

109. Ranque S, Normand AC, Cassagne C, et al. MALDI-TOF mass spectrometry identification of filamentous fungi in the clinical laboratory. Mycoses. 2014;57(3):135-140. doi:10.1111/myc.12115

110. Van Veen S, Claas E, Kuijper EJ. High-throughput identification of bacteria and yeast by matrix-assisted laser desorption ionization-time of flight mass spectrometry in conventional medical microbiology laboratories. J Clin Microbiol. 2010;48 (3):900-907. doi:10.1128/JCM.02071-09

111. Bizzini A, Durussel C, Bille J, Greub G, Prod'Hom G. Performance of matrix-assisted laser desorption ionization-time of flight mass spectrometry for identification of bacterial strains routinely isolated in a clinical microbiology laboratory. $\mathrm{J}$ Clin Microbiol. 2010;48(5):1549-1554. doi:10.1128/JCM.01794-09

112. Schubert S, Weinert K, Wagner C, et al. Novel, improved sample preparation for rapid, direct identification from positive blood cultures using matrix-assisted laser desorption/ionization time-offlight (MALDI-TOF) mass spectrometry. J Mol Diagn. 2011;13 (6):701-706. doi:10.1016/j.jmoldx.2011.07.004

113. Seng P, Drancourt M, Gouriet F, et al. Ongoing revolution in bacteriology: routine identification of bacteria by matrix-assisted laser desorption ionization time-of-flight mass spectrometry. Clin Infect Dis. 2009;49(4):543-551. doi:10.1086/600885

114. Niles D, Boguniewicz J, Shakeel O, et al. Candida tropicalis thyroiditis presenting with thyroid storm in a pediatric patient with acute lymphocytic leukemia. Pediatr Infect Dis J. 2019;38 (10):1051-1053. doi:10.1097/INF.0000000000002424

115. Ma L, Tong H, Ruan L, Ling Z, Ren Y, Zhou X. Successful treatment of Candida tropicalis osteomyelitis with Micafungin in a leukemia patient. IDCases. 2016;6:109. doi:10.1016/j. idcr.2016.10.002

116. Vicari P, Pinheiro RF, MdLLF C, Yamamoto M, Figueiredo MS. Septic arthritis as the first sign of Candida tropicalis fungaemia in an acute lymphoid leukemia patient. Braz J Infect Dis. 2003;7 (6):426-428. doi:10.1590/S1413-86702003000600012
117. Harada Y, Murata M, Matsumoto A, et al. [Successful treatment of pre-engraftment disseminated fusariosis with high-dose liposomal amphotericin B in a cord blood transplant recipient]. Rinsho Ketsueki. 2019;60(12):1641-1646. Japanese. doi:10.11406/rinketsu.60.1641

118. Ichikawa S, Fukuhara N, Watanabe $\mathrm{S}$, et al. Long-term survival after cord blood transplantation for acute myeloid leukemia complicated with disseminated fusariosis. J Infect Chemother. 2020;26(2):292-295. doi:10.1016/j.jiac.2019.08.022

119. Mardani M, Khodashahi R, Lotfali E, Abolghasemi S, HakemiVala M. Disseminated fusariosis with ecthyma gangrenosum-like lesions in a refractory acute myeloid leukemia patient. Curr Med Mycol. 2019;5(1):27-31. doi:10.18502/cmm.5.1.534

120. Delia M, Monno R, Giannelli G, et al. Fusariosis in a patient with acute myeloid leukemia: a case report and review of the literature. Mycopathologia. 2016;181(5-6):457-463. doi:10.1007/s11046016-9987-5

121. Fadhel M, Patel SV, Liu E, Fune L, Wasserman EJ, Asif A. Disseminated pulmonary with isolated muscular mucormycosis in an acute myeloid leukemia patient: a case report and literature review. Am J Case Rep. 2019;20:1210-1215. doi:10.12659/ AJCR.916864

122. Miura K, Kobayashi N, Ito I, et al. Pulmonary mucormycosis developed during acute myelogenous leukemia and successfully treated by surgical resection before blood stem cell transplantation. AME Case Rep. 2019;3:48. doi:10.21037/ acr.2019.11.02

123. Biddeci G, Antonello M, Pizzi M, et al. Mucormycosis with peculiar aortic involvement in a child with acute lymphoblastic leukemia. Pediatr Hematol Oncol. 2019;1-6.

124. Jeurkar C, Margetich L, Sahin Z. Mucormycosis leading to cerebral edema and cerebellar tonsillar herniation after allogeneic bone marrow transplant: a case report. Case Rep Infect Dis. 2019;2019:5138198.

125. Ozhak-Baysan B, Alastruey-Izquierdo A, Saba R, et al. Aspergillus alliaceus and Aspergillus flavus co-infection in an acute myeloid leukemia patient. Med Mycol. 2010;48 (7):995-999. doi:10.3109/13693781003749418

126. Le T-H, Kumar V, Gondal K, et al. Isolated central nervous system Aspergillosis infection in a chronic lymphocytic leukemia patient on Ibrutinib: A case report. BMC Infect Dis. 2020;20 (1):1-3. doi:10.1186/s12879-020-4894-2

127. Rößler S, Bader O, Stölzel F, et al. Progressive dispersion of azole resistance in Aspergillus fumigatus: fatal invasive Aspergillosis in a patient with acute myeloid leukemia infected with an A. fumigatus strain with a cyp51A TR46 Y121F M172I T289A Allele. Antimicrob Agents Chemother. 2017;61(8): e00270-00217. doi:10.1128/AAC.00270-17

128. Antonogiannaki E-M, Proklou A, Tamiolakis D, Vassalou E, Kondili E. Invasive Aspergillus tracheobronchitis in a patient with hairy cell leukemia and previous Plasmodium falciparum infection. Monaldi Arch Chest Dis. 2019;89:2. doi:10.4081/ monaldi.2019.1055

129. Turki AT, Rashidi-Alavijeh J, Dürig J, Gerken G, Rath P-M WO. Successful treatment of cerebral aspergillosis: case report of a patient with T-cell large granular lymphocytic leukemia (T-LGL). BMC Infect Dis. 2017;17(1):797. doi:10.1186/s12879. 017-2877-8

130. Inoue $\mathrm{H}$, Motohashi $\mathrm{T}$, Ioku $\mathrm{Y}$, Watanabe $\mathrm{M}$, Nakajima $\mathrm{M}$, Sugitatsu M. The detection of Cryptococcus in skeletal infection after tooth extraction in an acute myeloid leukemia patient. IDCases. 2020;19:e0700. doi:10.1016/j.idcr.2020.e00700

131. Ramírez I, Moncada D. Fatal disseminated infection by trichosporon asahii under voriconazole therapy in a patient with acute myeloid leukemia: a review of breakthrough infections by trichosporon spp. Mycopathologia. 2019;1-12. 
132. Nguyen JK, Schlichte MJ, Schady D, Pourciau CY. Fatal disseminated Trichosporon asahii fungemia in a child with acute lymphoblastic leukemia and a morbilliform eruption. Pediatr Dermatol. 2018;35(1):e86-e87. doi:10.1111/pde.13359

133. Neofytos D, Horn D, Anaissie E, et al. Epidemiology and outcome of invasive fungal infection in adult hematopoietic stem cell transplant recipients: analysis of Multicenter Prospective Antifungal Therapy (PATH) Alliance registry. Clin Infect Dis. 2009;48(3):265-273. doi:10.1086/595846

134. Kwon-Chung KJ. Taxonomy of fungi causing mucormycosis and entomophthoramycosis (zygomycosis) and nomenclature of the disease: molecular mycologic perspectives. Clin Infect Dis. 2012;54(suppl_1):S8-S15. doi:10.1093/cid/cir864

135. Gomes MZ, Lewis RE, Kontoyiannis DP. Mucormycosis caused by unusual mucormycetes, non-Rhizopus,-Mucor, and-Lichtheimia species. Clin Microbiol Rev. 2011;24(2):411-445.

136. Sipsas NV, Gamaletsou MN, Anastasopoulou A, Kontoyiannis DP. Therapy of mucormycosis. J Fungi (Basel). 2018;4:3.

137. Walsh T, Groll A, Hiemenz J, Fleming R, Roilides E, Anaissie E. Infections due to emerging and uncommon medically important fungal pathogens. Clin Microbiol Infect. 2004;10:48-66. doi:10.1111/j.1470-9465.2004.00839.x

138. Greenberg RN, Scott LJ, Vaughn HH, Ribes JA. Zygomycosis (mucormycosis): emerging clinical importance and new treatments. Curr Opin Infect Dis. 2004;17(6):517-525. doi:10.1097/00001432-200412000-00003

139. Noorifard M, Sekhavati E, Jalaei Khoo H, Hazraty I, Tabrizi R. Epidemiology and clinical manifestation of fungal infection related to Mucormycosis in hematologic malignancies. $J$ Med Life. 2015;8(SpecIss 2):32-37.

140. Andresen D, Donaldson A, Choo L, et al. Multifocal cutaneous mucormycosis complicating polymicrobial wound infections in a tsunami survivor from Sri Lanka. The Lancet. 2005;365 (9462):876-878. doi:10.1016/S0140-6736(05)71046-1

141. Neblett Fanfair R, Benedict K, Bos J, et al. Necrotizing cutaneous mucormycosis after a tornado in Joplin, Missouri, in 2011. N Engl $J$ Med. 2012;367(23):2214-2225. doi:10.1056/NEJMoa1204781

142. Warkentien T, Rodriguez C, Lloyd B, et al. Invasive mold infections following combat-related injuries. Clin Infect Dis. 2012;55 (11):1441-1449. doi:10.1093/cid/cis749

143. Paramythiotou E, Frantzeskaki F, Flevari A, Armaganidis A, Dimopoulos G. Invasive fungal infections in the ICU: how to approach, how to treat. Molecules. 2014;19(1):1085-1119. doi:10.3390/molecules 19011085

144. Poirier P, Nourrisson C, Gibold L, et al. Three cases of cutaneous mucormycosis with Lichtheimia spp. (ex Absidia/Mycocladus) in ICU. Possible cross-transmission in an intensive care unit between 2 cases. Journal de mycologie médicale. 2013;23 (4):265-269. doi:10.1016/j.mycmed.2013.09.002

145. Machicado JD, Younes M, Wolf DS. A rare cause of gastrointestinal bleeding in the intensive care unit. Gastroenterology. 2014;146(4):1136-1137. doi:10.1053/j.gastro.2013.11.038

146. Sipsas NV, Kontoyiannis DP. Invasive fungal infections in patients with cancer in the Intensive Care Unit. Int $J$ Antimicrob Agents. 2012;39(6):464 471. doi:10.1016/j.ijantimicag.2011.11.017

147. Kontoyiannis DP, Wessel VC, Bodey GP, Rolston KV. Zygomycosis in the 1990s in a tertiary-care cancer center. Clin Infect Dis. 2000;30(6):851-856. doi:10.1086/313803

148. Roden MM, Zaoutis TE, Buchanan WL, et al. Epidemiology and outcome of zygomycosis: a review of 929 reported cases. Clin Infect Dis. 2005;41(5):634-653.

149. Skiada A, Pagano L, Groll A, et al. Zygomycosis in Europe: analysis of 230 cases accrued by the registry of the European Confederation of Medical Mycology (ECMM) Working Group on Zygomycosis between 2005 and 2007. Clin Microbiol Infect. 2011;17(12):1859-1867. doi:10.1111/j.1469-0691.2010.03456.x
150. Chamilos G, Marom EM, Lewis RE, Lionakis MS, Kontoyiannis DP. Predictors of pulmonary zygomycosis versus invasive pulmonary aspergillosis in patients with cancer. Clin Infect Dis. 2005;41(1):60-66. doi:10.1086/430710

151. Arnáiz-García M, Alonso-Pena D, Del Carmen González-Vela M, García-Palomo J, Sanz-Giménez-Rico J, Arnáiz-García A. Cutaneous mucormycosis: report of five cases and review of the literature. J Plast Reconstruct Aesthetic Surg. 2009;62(11):e434e441.. doi:10.1016/j.bjps.2008.04.040

152. Prabhu R, Patel R. Mucormycosis and entomophthoramycosis: a review of the clinical manifestations, diagnosis and treatment. Clin Microbiol Infect. 2004;10:31-47. doi:10.1111/j.14709465.2004.00843.x

153. Marty FM, Ostrosky-Zeichner L, Cornely OA, et al. Isavuconazole treatment for mucormycosis: a single-arm open-label trial and case-control analysis. Lancet Infect Dis. 2016;16(7):828-837. doi:10.1016/S1473-3099(16)00071-2

154. Nagappan V, Deresinski S. Posaconazole: a broad-spectrum triazole antifungal agent. Clin Infect Dis. 2007;45(12):1610-1617. doi: $10.1086 / 523576$

155. Spellberg B, Ibrahim A, Roilides E, et al. Combination therapy for mucormycosis: why, what, and how? Clin Infect Dis. 2012;54 (suppl_1):S73-S78. doi:10.1093/cid/cir885

156. Kyvernitakis A, Torres HA, Jiang Y, Chamilos G, Lewis R, Kontoyiannis DP. Initial use of combination treatment does not impact survival of 106 patients with haematologic malignancies and mucormycosis: a propensity score analysis. Clin Microbiol Infect. 2016;22(9):811.e811-811. e818. doi:10.1016/j. cmi.2016.03.029

157. Reed C, Bryant R, Ibrahim AS, et al. Combination polyene-caspofungin treatment of rhino-orbital-cerebral mucormycosis. Clin Infect Dis. 2008;47(3):364-371. doi:10.1086/589857

158. Skiada A, Lanternier F, Groll AH, et al. Diagnosis and treatment of mucormycosis in patients with hematological malignancies: guidelines from the 3rd European Conference on Infections in Leukemia (ECIL 3). haematologica. 2019;3(7):492-504. doi:10.3324/haematol.2012.065110

159. Abzug MJ, Walsh TJ. Interferon-? and colony-stimulating factors as adjuvant therapy for refractory fungal infections in children. Pediatr Infect Dis J. 2009;62(11):769-773. doi:10.1097/01. inf.0000134314.65398.bf

160. Gil-Lamaignere C, Simitsopoulou M, Roilides E, Maloukou A, Winn RM, Walsh TJ. Interferon- $\gamma$ and granulocyte-macrophage colony-stimulating factor augment the activity of polymorphonuclear leukocytes against medically important zygomycetes. J Infect Dis. 2005;191(7):1180-1187. doi:10.1086/428503

161. Dale DC, Liles WC, Llewellyn C, Price TH. Effects of granulocyte-macrophage colony-stimulating factor (GM-CSF) on neutrophil kinetics and function in normal human volunteers. $\mathrm{Am}$ $J$ Hematol. 1998;57(1):7-15. doi:10.1002/(SICI)1096-8652(199801)57:1<7::AID-AJH2>3.0.CO;2-0

162. Kapp A, Zeck-Kapp G. Activation of the oxidative metabolism in human polymorphonuclear neutrophilic granulocytes: the role of immuno-modulating cytokines. J Investig Dermatol. 1990;95.

163. Hübel K, Dale DC, Engert A, Liles WC. Current status of granulocyte (neutrophil) transfusion therapy for infectious diseases. J Infect Dis. 2001;183(2):321-328. doi:10.1086/317943

164. Chamilos G, Lewis RE, Kontoyiannis DP. Delaying amphotericin B-based frontline therapy significantly increases mortality among patients with hematologic malignancy who have zygomycosis. Clin Infect Dis. 2008;47(4):503-509. doi:10.1086/590004

165. Mohindra S, Mohindra S, Gupta R, Bakshi J, Gupta SK. Rhinocerebral mucormycosis: the disease spectrum in 27 patients. Mycoses. 2007;50 (4):290-296. doi:10.1111/j.1439-0507.2007.01364.x 
166. Tedder M, Spratt JA, Anstadt MP, Hegde SS, Tedder SD, Lowe JE. Pulmonary mucormycosis: results of medical and surgical therapy. Ann Thorac Surg. 1994;57(4):1044-1050. doi:10.1016/0003-4975(94)90243-7

167. Chakrabarti A, Das A, Mandal J, et al. The rising trend of invasive zygomycosis in patients with uncontrolled diabetes mellitus. Sabouraudia. 2006;44(4):335-342. doi:10.1080/ 13693780500464930

168. Yamamichi T, Horio H, Asakawa A, Okui M, Harada M. Surgery for pulmonary fungal infections complicating hematological malignancies. Korean J Thorac Cardiovasc Surg. 2018;51 (5):350-355. doi:10.5090/kjtcs.2018.51.5.350

169. Tarrand JJ, Lichterfeld M, Warraich I, et al. Diagnosis of invasive septate mold infections: a correlation of microbiological culture and histologic or cytologic examination. Am J Clin Pathol. 2003;119(6):854-858. doi:10.1309/EXBVYAUPENBM285Y

170. Lass-Florl C. Zygomycosis: conventional laboratory diagnosis. Clin Microbiol Infect. 2009;15(Suppl 5):60-65. doi:10.1111/ j.1469-0691.2009.02999.x

171. Jeong W, Keighley C, Wolfe R, et al. The epidemiology and clinical manifestations of mucormycosis: a systematic review and meta-analysis of case reports. Clin Microbiol Infect. 2019;25(1):26-34. doi:10.1016/j.cmi.2018.07.011

172. Millon L, Larosa F, Lepiller Q, et al. Quantitative polymerase chain reaction detection of circulating DNA in serum for early diagnosis of mucormycosis in immunocompromised patients. Clin Infect Dis. 2013;56(10):e95-101. doi:10.1093/cid/cit094

173. Millon L, Herbrecht R, Grenouillet F, et al. Early diagnosis and monitoring of mucormycosis by detection of circulating DNA in serum: retrospective analysis of 44 cases collected through the French Surveillance Network of Invasive Fungal Infections (RESSIF). Clin Microbiol Infect. 2016;22(9):810.e811-810. e818. doi:10.1016/j.cmi.2015.12.006

174. Hammond SP, Bialek R, Milner DA, Petschnigg EM, Baden LR, Marty FM. Molecular methods to improve diagnosis and identification of mucormycosis. J Clin Microbiol. 2011;49 (6):2151-2153. doi:10.1128/JCM.00256-11

175. Bellanger AP, Rocchi S, Berceanu A, Scherer E, Larosa F, Millon L. Positive quantitative PCR detecting Fusarium solani in a case of mixed invasive fungal disease due to Mucorales and Fusarium solani. Bone Marrow Transplant. 2020;55(5):873-876. doi:10.1038/s41409-020-0819-3

176. Shadrivova OV, Burygina EV, Klimko NN. Molecular diagnostics of mucormycosis in hematological patients: a literature review. J Fungi. 2019;5(4):112. doi:10.3390/jof5040112

177. Camara-Lemarroy CR, Gonzalez-Moreno EI, Rodriguez-Gutierrez $\mathrm{R}$, et al. Clinical features and outcome of mucormycosis. Interdiscip Perspect Infect Dis. 2014;2014:562610. doi:10.1155/2014/562610

178. Zhang Y, Yang H, Turra D, et al. The genome of opportunistic fungal pathogen Fusarium oxysporum carries a unique set of lineage-specific chromosomes. Commun Biol. 2020;3(1):50. doi:10.1038/s42003-020-0770-2

179. Nucci M, Anaissie E. Fusarium infections in immunocompromised patients. Clin Microbiol Rev. 2007;20(4):695-704. doi:10.1128/CMR.00014-07

180. Litvinov N, da Silva MTN, van der Heijden IM, et al. An outbreak of invasive fusariosis in a children's cancer hospital. Clin Microbiol Infect. 2015;21(3):268.e261-268. e267. doi:10.1016/j. cmi.2014.09.004

181. Short DP, O’Donnell K, Zhang N, Juba JH, Geiser DM. Widespread occurrence of diverse human pathogenic types of the fungus Fusarium detected in plumbing drains. $J$ Clin Microbiol. 2011;49(12):4264-4272. doi:10.1128/JCM.05468-11

182. Nucci F, Nouer SA, Capone D, Anaissie E, Nucci M Fusariosis. Paper presented at: Seminars in respiratory and critical care medicine; 2015.
183. Nucci M, Anaissie EJ, Queiroz-Telles F, et al. Outcome predictors of 84 patients with hematologic malignancies and Fusarium infection. Cancer. 2003;98(2):315-319. doi:10.1002/cncr.11510

184. Nucci M, Anaissie E. Emerging fungi. Infect Dis Clin. 2006;20 (3):563-579. doi:10.1016/j.idc.2006.06.002

185. Sander A, Beyer U, Amberg R. Systemic Fusarium oxysporum infection in an immunocompetent patient with an adult respiratory distress syndrome (ARDS) and extracorporal membrane oxygenation (ECMO). Mycoses. 1998;41(3-4):109-111. doi:10.1111/j.1439-0507.1998.tb00310.x

186. Kurien M, Anandi V, Raman R, Brahmadathan KN. Maxillary sinus fusariosis in immunocompetent hosts. $J$ Laryngol Otol. 1992;106(8):733-736. doi:10.1017/S0022215100120729

187. Hiebert RM, Welliver RC, Yu Z. Fusarium osteomyelitis in a patient with pearson syndrome: case report and review of the literature. Open Forum Infect Dis. 2016;3(4):ofw183. doi:10.1093/ofid/ofw183

188. Proenca-Pina J, Ssi Yan Kai I, Bourcier T, Fabre M, Offret H, Labetoulle M. Fusarium keratitis and endophthalmitis associated with lens contact wear. Int Ophthalmol. 2010;30(1):103-107. doi:10.1007/s10792-008-9290-7

189. Nucci M, Anaissie E. Cutaneous infection by Fusarium species in healthy and immunocompromised hosts: implications for diagnosis and management. Clin Infect Dis. 2002;35(8):909-920. doi: $10.1086 / 342328$

190. Torres HA, Raad II, Kontoyiannis DP. Infections caused by Fusarium species. $J$ Chemother. 2003;15(sup2):28-35. doi:10.1179/joc.2003.15.Supplement-2.28

191. Nelson PE, Dignani MC, Anaissie EJ. Taxonomy, biology, and clinical aspects of Fusarium species. Clin Microbiol Rev. 1994;7 (4):479-504. doi:10.1128/CMR.7.4.479

192. Azor M, Gené J, Cano J, Manikandan P, Venkatapathy N, Guarro J. Less-frequent Fusarium species of clinical interest: correlation between morphological and molecular identification and antifungal susceptibility. $J$ Clin Microbiol. 2009;47 (5):1463-1468. doi:10.1128/JCM.02467-08

193. Wu CH, Lu PL, Hsiao HH, et al. Breakthrough Fusarium solani infection in a patient with acute myeloid leukemia receiving posaconazole prophylaxis. Ann Hematol. 2014;93(6):1079-1081. doi:10.1007/s00277-013-1943-6

194. Lerolle N, Raffoux E, Socie G, et al. Breakthrough invasive fungal disease in patients receiving posaconazole primary prophylaxis: a 4-year study. Clin Microbiol Infect. 2014;20(11): O952-959. doi:10.1111/1469-0691.12688

195. Sautour M, Edel-Hermann V, Steinberg C, et al. Fusarium species recovered from the water distribution system of a French university hospital. Int J Hyg Environ Health. 2012;215(3):286-292. doi:10.1016/j.ijheh.2011.11.003

196. Guarro J. Lessons from animal studies for the treatment of invasive human infections due to uncommon fungi. J Antimicrob Chemother. 2011;66(7):1447-1466. doi:10.1093/jac/dkr143

197. Odds F, Van Gerven F, Espinel-Ingroff A, et al. Evaluation of possible correlations between antifungal susceptibilities of filamentous fungi in vitro and antifungal treatment outcomes in animal infection models. Antimicrob Agents Chemother. 1998;42 (2):282-288. doi:10.1128/AAC.42.2.282

198. Guarro J. Fusariosis, a complex infection caused by a high diversity of fungal species refractory to treatment. Eur J Clin Microbiol Infect Dis. 2013;32(12):1491-1500. doi:10.1007/s10096-013-1924-7

199. Arnoni MV, Paula CR, Auler ME, et al. Infections caused by fusarium species in pediatric cancer patients and review of published literature. Mycopathologia. 2018;183(6):941-949. doi:10.1007/s11046-018-0257-6

200. Espinel-Ingroff A, Colombo A, Cordoba S, et al. International evaluation of MIC distributions and epidemiological cutoff value (ECV) definitions for Fusarium species identified by molecular methods for the CLSI broth microdilution method. Antimicrob Agents Chemother. 2016;60(2):1079-1084. doi:10.1128/AAC.02456-15 
201. Yu J, Chen Y, Fang J, Zhang K. Successful treatment of disseminated fusariosis in a patient with acute lymphoblastic leukemia: a case report and literature review. Medicine (Baltimore). 2019;98 (26):e16246. doi:10.1097/MD.0000000000016246

202. Pereira GH, de Angelis DA, Brasil RA, et al. Disseminated amphotericin-resistant fusariosis in acute leukemia patients: report of two cases. Mycopathologia. 2013;175(1-2):107-114. doi:10.1007/s11046-012-9585-0

203. Liu K, Howell DN, Perfect JR, Schell WA. Morphologic criteria for the preliminary identification of Fusarium, Paecilomyces, and Acremonium species by histopathology. Am J Clin Pathol. 1998;109(1):45-54. doi:10.1093/ajcp/109.1.45

204. Odabasi Z, Mattiuzzi G, Estey E, et al. $\beta$-D-glucan as a diagnostic adjunct for invasive fungal infections: validation, cutoff development, and performance in patients with acute myelogenous leukemia and myelodysplastic syndrome. Clin Infect Dis. 2004;39 (2):199-205. doi:10.1086/421944

205. Ostrosky-Zeichner L, Alexander BD, Kett DH, et al. Multicenter clinical evaluation of the $(1 \rightarrow 3) \beta$-D-glucan assay as an aid to diagnosis of fungal infections in humans. Clin Infect Dis. 2005;41 (5):654-659. doi:10.1086/432470

206. Herkert PF, AMS A-H, de Oliveira Salvador GL, et al. Molecular characterization and antifungal susceptibility of clinical fusarium species from Brazil. Front Microbiol. 2019;10:737. doi:10.3389/ fmicb.2019.00737

207. Ngamskulrungroj P, Gilgado F, Faganello J, et al. Genetic diversity of the Cryptococcus species complex suggests that Cryptococcus gattii deserves to have varieties. PLoS One. 2009;4:6. doi:10.1371/ annotation/3037bb69-1b8e-4d99-b169-afdf4b74ace2

208. Chastain DB, Henao-Martínez AF, Franco-Paredes C. Opportunistic invasive mycoses in AIDS: cryptococcosis, histoplasmosis, coccidiodomycosis, and talaromycosis. Curr Infect Dis Rep. 2017;19(10):36. doi:10.1007/s11908-017-0592-7

209. CdC S, Wirth F, Lopes LB, Ishida K. New approaches for cryptococcosis treatment. Microorganisms. 2020;8(4):613. doi:10.33 90/microorganisms 8040613

210. Shao X, Mednick A, Alvarez M, Van Rooijen N, Casadevall A, Goldman DL. An innate immune system cell is a major determinant of species-related susceptibility differences to fungal pneumonia. J Immunol. 2005;175(5):3244-3251. doi:10.4049/jimmunol.175.5.3244

211. Goldman DL, Fries BC, Franzot SP, Montella L, Casadevall A. Phenotypic switching in the human pathogenic fungus Cryptococcus neoformans is associated with changes in virulence and pulmonary inflammatory response in rodents. Proc Natl Acad Sci. 1998;95(25):14967-14972. doi:10.1073/pnas.95.25.14967

212. Bouklas T, Pechuan X, Goldman DL, Edelman B, Bergman A, Fries BC. Old Cryptococcus neoformans cells contribute to virulence in chronic cryptococcosis. MBio. 2013;4(4):e00455-00413. doi: $10.1128 / \mathrm{mBio} .00455-13$

213. Park BJ, Wannemuehler KA, Marston BJ, Govender N, Pappas PG, Chiller TM. Estimation of the current global burden of cryptococcal meningitis among persons living with HIV/AIDS. AIDS. 2009;23(4):525-530. doi:10.1097/QAD.0b013e328322ffac

214. Shirley RM, Baddley JW. Cryptococcal lung disease. Curr Opin Pulm Med. 2009;15(3):254-260. doi:10.1097/MCP.0b013e328329268d

215. Kao C, Goldman DL. Cryptococcal disease in HIV-infected children. Curr Infect Dis Rep. 2016;18(9):27. doi:10.1007/ s11908-016-0534-9

216. Pappas PG, Perfect JR, Cloud GA, et al. Cryptococcosis in human immunodeficiency virus-negative patients in the era of effective azole therapy. Clin Infect Dis. 2001;33(5):690-699. doi:10.1086/322597

217. Marchand T, Revest M, Tattevin P, et al. Early cryptococcal meningitis following treatment with rituximab, fludarabine and cyclophosphamide in a patient with chronic lymphocytic leukemia. Leuk Lymphoma. 2013;54(3):643-645. doi:10.3109/ 10428194.2012.717081
218. Morrison VA. Infectious complications in patients with chronic lymphocytic leukemia: pathogenesis, spectrum of infection, and approaches to prophylaxis. Clin Lymphoma Myeloma. 2009;9 (5):365-370. doi:10.3816/CLM.2009.n.071

219. Stankowicz M, Banaszynski M, Crawford R. Cryptococcal infections in two patients receiving ibrutinib therapy for chronic lymphocytic leukemia. J Oncol Pharm Pract. 2019;25(3):710-714. doi:10.1177/1078155217752078

220. Allahmoradi E, Taghiloo S, Tehrani M, et al. CD4+ T cells are exhausted and show functional defects in chronic lymphocytic leukemia. Iran J Immunol. 2017;14(4):257-269.

221. Park SS, Lee H, Park WS, et al. A case of disseminated infection with skin manifestation due to non-neoformans and non-gattii Cryptococcus in a patient with refractory acute myeloid leukemia. Infect Chemother. 2017;49(2):142-145. doi:10.3947/ ic.2017.49.2.142

222. Khan Z, Mokaddas E, Ahmad S, Burhamah MH. Isolation of Cryptococcus magnus and Cryptococcus chernovii from nasal cavities of pediatric patients with acute lymphoblastic leukemia. Med Mycol. 2011;49(4):439-443. doi:10.3109/13693786.2010.530696

223. Limper AH, Adenis A, Le T, Harrison TS. Fungal infections in HIV/AIDS. Lancet Infect Dis. 2017;17(11):e334-e343. doi:10.1016/S1473-3099(17)30303-1

224. Boulware DR, Rolfes MA, Rajasingham R, et al. Multisite validation of cryptococcal antigen lateral flow assay and quantification by laser thermal contrast. Emerg Infect Dis. 2014;20(1):45. doi:10.3201/eid2001.130906

225. Williams DA, Kiiza T, Kwizera R, et al. Evaluation of fingerstick cryptococcal antigen lateral flow assay in HIV-infected persons: a diagnostic accuracy study. Clin Infect Dis. 2015;61(3):464-467. doi:10.1093/cid/civ263

226. Bongomin F, Oladele RO, Gago S, Moore CB, Richardson MD. A systematic review of fluconazole resistance in clinical isolates of Cryptococcus species. Mycoses. 2018;61(5):290-297. doi: $10.1111 /$ myc. 12747

227. Assing K, Birgens H, Arendrup M. Cryptococcus neoformans var. neoformans resistant to fluconazole in an HIV-negative patient with chronic lymphocytic leukemia. Clin Microbiol Infect. 2003;9 (5):441-444. doi:10.1046/j.1469-0691.2003.00571.x

228. Kawakami K, Tohyama M, Teruya K, Kudeken N, Xie Q, Saito A. Contribution of interferon- $\gamma$ in protecting mice during pulmonary and disseminated infection with Cryptococcus neoformans. FEMS Immunol Med Microbiol. 1996;13(2):123-130.

229. Nooney L, Matthews RC, Burnie JP. Evaluation of Mycograb ${ }^{\circledR}$, amphotericin B, caspofungin, and fluconazole in combination against Cryptococcus neoformans by checkerboard and time-kill methodologies. Diagn Microbiol Infect Dis. 2005;51(1):19-29. doi:10.1016/j.diagmicrobio.2004.08.013

230. Larsen RA, Pappas PG, Perfect J, et al. Phase I evaluation of the safety and pharmacokinetics of murine-derived anticryptococcal antibody 18B7 in subjects with treated cryptococcal meningitis. Antimicrob Agents Chemother. 2005;49(3):952-958. doi:10.1128/ AAC.49.3.952-958.2005

231. Zhai B, Wu C, Wang L, Sachs MS, Lin X. The antidepressant sertraline provides a promising therapeutic option for neurotropic cryptococcal infections. Antimicrob Agents Chemother. 2012;56 (7):3758-3766. doi:10.1128/AAC.00212-12

232. Butts A, Koselny K, Chabrier-Roselló Y, et al. Estrogen receptor antagonists are anti-cryptococcal agents that directly bind EF hand proteins and synergize with fluconazole in vivo. MBio. 2014;5(1):e00765-00713. doi:10.1128/mBio.00765-13

233. Garg V, Jones E, Friedman BJ, Lee JB, Yang S Invasive trichosporonosis treated with voriconazole. 2018.

234. de Almeida Júnior JN, Hennequin C. Invasive trichosporon infection: a systematic review on a re-emerging fungal pathogen. Front Microbiol. 2016;7:1629. doi:10.3389/fmicb.2016.01629 
235. Foster CE, Edwards MS, Brackett J, Schady DA, Healy CM, Baker CJ. Trichosporonosis in pediatric patients with a hematologic disorder. J Pediatric Infect Dis Soc. 2018;7 (3):199-204. doi:10.1093/jpids/pix031

236. Maxfield L, Matthews JJ, Ambrosetti DR, Ephtimios IE. Trichosporon fungemia in a pediatric patient with acute lymphoblastic leukemia. IDCases. 2015;2(4):106-108. doi:10.1016/j.idcr.2015.09.007

237. Suzuki K, Nakase K, Kyo T, et al. Fatal Trichosporon fungemia in patients with hematologic malignancies. Eur J Haematol. 2010;84 (5):441-447. doi:10.1111/j.1600-0609.2010.01410.x

238. Kimura M, Araoka H, Yamamoto $\mathrm{H}$, et al. Micafungin breakthrough fungemia in patients with hematological disorders. Antimicrob Agents Chemother. 2018;62(5):e02183-02117. doi:10.1128/AAC.02183-17

239. Dos Santos CO, Zijlstra JG, Porte RJet al,. Emerging pan-resistance in Trichosporon species: a case report. $B M C$ Infect Dis. 2016;16(1):148. doi:10.1186/s12879-016-1477-3.

240. Karigane D, Sakurai M, Matsuyama E, et al. Successful treatment of breakthrough disseminated Trichosporon asahii fungemia in a patient with acute myeloid leukemia receiving itraconazole prophylaxis. Med Mycol Case Rep. 2018;20:1-3. doi:10.1016/j. mmcr.2017.11.006

241. Galligan ER, Fix L, Husain S, Zachariah P, Yamashiro DJ, Lauren CT. Disseminated trichosporonosis with atypical histologic findings in a patient with acute lymphocytic leukemia. J Cutan Pathol. 2019;46(2):159-161. doi:10.1111/cup.13397

242. Davies GE, Thornton CR. Differentiation of the emerging human pathogens Trichosporon asahii and Trichosporon asteroides from other pathogenic yeasts and moulds by using species-specific monoclonal antibodies. PLoS One. 2014;9:1. doi:10.1371/journal.pone.0084789

243. Obana Y, Sano M, Jike T, Homma T, Nemoto N. Differential diagnosis of trichosporonosis using conventional histopathological stains and electron microscopy. Histopathology. 2010;56 (3):372-383. doi:10.1111/j.1365-2559.2010.03477.x

244. Arendrup M, Boekhout T, Akova M, et al. ESCMID and ECMM joint clinical guidelines for the diagnosis and management of rare invasive yeast infections. Clin Microbiol Infect. 2014;20:76-98. doi:10.1111/1469-0691.12360

245. Hara S, Yokote T, Oka S, et al. Endophthalmitis due to Trichosporon beigelii in acute leukemia. Int J Hematol. 2007;85 (5):415-417. doi:10.1532/IJH97.06228

246. Vázquez-González D, Perusquía-Ortiz AM, Hundeiker M, Bonifaz A. Opportunistic yeast infections: candidiasis, cryptococcosis, trichosporonosis and geotrichosis. JDDG. 2013;11 (5):381-394. doi:10.1111/ddg.12097

247. Gross JW, Kan VL. Trichosporon asahii infection in an advanced AIDS patient and literature review. AIDS. 2008;22(6):793-795. doi:10.1097/QAD.0b013e3282f51ecc

248. Fan Y-M, Huang W-M, Yang Y-P, Li W, Li S-F. Primary cutaneous trichosporonosis caused by Trichosporon dermatis in an immunocompetent man. J Am Acad Dermatol. 2011;65 (2):434-436. doi:10.1016/j.jaad.2010.01.020

249. Matsue K, Uryu H, Koseki M, Asada N, Takeuchi M. Breakthrough trichosporonosis in patients with hematologic malignancies receiving micafungin. Clin Infect Dis. 2006;42 (6):753-757. doi:10.1086/500323

250. Tager D, Hatch A, Segar J, Roller B, Al Mohajer M, Zangeneh TT. Coccidioidal meningitis complicated by central nervous system vasculitis in a patient with leukemia. Med Mycol Case Rep. 2017;16:8-11. doi:10.1016/j.mmcr.2017.03.003

251. Kurata K, Nishimura S, Ichikawa $H$, et al. Invasive Scopulariopsis alboflavescens infection in patient with acute myeloid leukemia. Int J Hematol. 2018;108(6):658-664. doi:10.1007/ s12185-018-2496-1
252. Yang Q, Wei J, Chen Z. Fatal bronchial invasion of Scopulariopsis brevicaulis in an acute monocytic leukemia patient. Diagn Microbiol Infect Dis. 2012;73(4):369-371. doi:10.1016/j.diagmicrobio.2012.04.010

253. Gluck O, Segal N, Yariv F, et al. Pediatric invasive sinonasal Scopulariopsis brevicaulis-a case report and literature review. Int $J$ Pediatr Otorhinolaryngol. 2011;75(7):891-893. doi:10.1016/j.ijporl.2011.03.026

254. Ng KP, Soo-Hoo TS, Na SL, Gan GG, Sangkar JV, Teh AK. Scopulariopsis brevicaulis infection in a patient with acute myeloid leukemia. Med J Malaysia. 2003;58(4):608-612.

255. Gavril D, Woerther PL, Ben Lakhdar A, et al. Invasive cutaneous infection due to Scopulariopsis brevicaulis unsuccessfully treated with high-dose micafungin in a neutropenic patient. Infection. 2017;45(3):361-363. doi:10.1007/s15010016-0971-2

256. Oya S, Muta T. Breakthrough infection of Geotrichum capitatum during empirical caspofungin therapy after umbilical cord blood transplantation. Int J Hematol. 2018;108(5):558-563. doi:10.1007/s12185-018-2481-8

257. Parkan OM, Atalay MA, Koc AN, Pala C, Aydemir G, Kaynar L. [Fungemia and septic arthritis caused by Saprochaete capitata in a patient with fanconi aplastic anemia: a case report]. Mikrobiyol Bul. 2017;51(1):87-93. Turkish. doi:10.5578/mb.33176

258. Ikuta K, Torimoto Y, Yamamoto M, et al. Successful treatment of systemic Geotrichum capitatum infection by liposomal amphotericin-B, itraconazole, and voriconazole in a Japanese man. Intern Med. 2010;49(22):2499-2503. doi:10.2169/ internalmedicine.49.3887

259. Fianchi L, Montini L, Caira M, et al. Combined voriconazole plus caspofungin therapy for the treatment of probable Geotrichum pneumonia in a leukemia patient. Infection. 2008;36(1):65-67. doi:10.1007/s15010-007-6235-4

260. Gao GX, Tang HL, Zhang X, Xin XL, Feng J, Chen XQ. Invasive fungal infection caused by geotrichum capitatum in patients with acute lymphoblastic leukemia: a case study and literature review. Int J Clin Exp Med. 2015;8(8):14228-14235.

261. Fukushima N, Mannen K, Okamoto S, Shinogi T, Nishimoto K, Sueoka E. Disseminated Ochroconis gallopavum infection in a chronic lymphocytic leukemia: a case report and review of the literature on hematological malignancies. Intern Med. 2005;44(8):879-882. doi:10.2169/ internalmedicine.44.879

262. Tong SY, Peleg AY, Yoong J, Handke R, Szer J, Slavin M. Breakthrough Scedosporium prolificans infection while receiving voriconazole prophylaxis in an allogeneic stem cell transplant recipient. Transpl Infect Dis. 2007;9(3):241-243. doi:10.1111/ j.1399-3062.2007.00203.x

263. García-Ruiz JC, Amutio E, Hernández I, et al. Clinical resolution of Scedosporium prolificans pneumonia associated with treatment with liposomal amphotericin B in a patient with acute leukemia. Rev Iberoam Micol. 1998;15(3):158-159.

264. Hanmantgad M, Nog R, Seiter K. Acute myeloid leukemia and fatal Scedosporium prolificans sepsis after eculizumab treatment for paroxysmal nocturnal hemoglobinuria: a case report. Stem Cell Investig. 2017;4:100. doi:10.21037/sci.2017.12.04

265. Ochi Y, Hiramoto N, Takegawa H, et al. Infective endocarditis caused by Scedosporium prolificans infection in a patient with acute myeloid leukemia undergoing induction chemotherapy. Int $\mathrm{J}$ Hematol. 2015;101(6):620-625. doi:10.1007/s12185-015-1752-x 


\section{Publish your work in this journal}

Infection and Drug Resistance is an international, peer-reviewed openaccess journal that focuses on the optimal treatment of infection (bacterial, fungal and viral) and the development and institution of preventive strategies to minimize the development and spread of resistance. The journal is specifically concerned with the epidemiology of antibiotic resistance and the mechanisms of resistance development and diffusion in both hospitals and the community. The manuscript management system is completely online and includes a very quick and fair peerreview system, which is all easy to use. Visit http://www.dovepress.com/ testimonials.php to read real quotes from published authors. 